\title{
Using a brief 11-item version of the RCADS to identify anxiety and depressive disorders in adolescents
}

\author{
Jerica Radez ${ }^{1}$, Polly Waite ${ }^{1,2}$, Bruce Chorpita ${ }^{4}$, Cathy Creswell ${ }^{2}$, Faith Orchard ${ }^{1}$, \\ Ray Percy ${ }^{1}$, Susan H. Spence ${ }^{3}$, and Tessa Reardon ${ }^{2}$ \\ ${ }^{1}$ School of Psychology and Clinical Language Sciences, University of Reading, Reading, UK \\ ${ }^{2}$ Departments of Experimental Psychology and Psychiatry, University of Oxford, Oxford, \\ UK \\ ${ }^{3}$ School of Applied Psychology and Australian Institute of Suicide Research and Prevention, \\ Griffith University \\ ${ }^{4}$ Department of Psychology, University of California, Los Angeles. \\ *Correspondence to p.l.waite@reading.ac.uk and polly.waite@psych.ox.ac.uk
}

\section{Acknowledgements}

JR is funded by the University of Reading through an Anniversary PhD Scholarship. PW is supported by an NIHR Post-Doctoral Fellowship (PDF-2016-09-092). CC and TR were supported by an NIHR Research Professorship to CC (RP_2014-04-018). The views expressed are those of the authors and not necessarily those of the NHS, the NIHR or the Department of Health.

The authors thank participating schools, families, the staff at the AnDY Research Clinic, University of Reading, Berkshire Healthcare NHS Foundation Trust for their involvement with the ethics, and Sairah Yunus and Brooke Watson, MSc students of the University of Reading, for their help with collecting the data. The authors also thank Prof Kou Murayama of the University of Reading for his advice on certain statistical procedures. The research materials can be accessed by contacting the corresponding author.

\section{Copyright statement}

The RCADS and its derivates are copyrighted by Bruce F. Chorpita and Susan H. Spence. They are available for use through Dr. Chorpita's UCLA resource page at no cost (www.childfirst.ucla.edu/resources.html). Any use of these instruments implies that the user has read and agreed to the terms of use.

\section{Disclosure statement}

The authors declare that they have no conflict of interest. 


\section{Using a brief 11-item version of the RCADS to identify anxiety and depressive disorders in adolescents}

Objective: The purpose of this study was to identify items from the Revised Children's Anxiety and Depression Scale - RCADS-C/P that provided a brief, reliable and valid screen for anxiety and/or depressive disorders in adolescents. In addition, we examined whether adding items assessing suicidal ideation (Moods and Feelings Questionnaire - MFQ-C/P) and symptom impact and duration (items adapted from the Strengths and Difficulties Questionnaire - SDQ) improved the identification of adolescents with anxiety and/or depressive disorders.

Methods: We compared two samples of adolescents and their parents - a community sample, recruited through secondary schools in England $(n=214)$ and a clinic-referred sample, who met diagnostic criteria for an anxiety and/or depressive disorder and were recruited through a university-based research clinic $(n=246)$. Participants completed the RCADS-C/P with additional symptom impact and duration items, and the MFQ-C/P.

Results: Using ROC curve analyses, we identified a set of 11 RCADS-C/P items (6 addressing anxiety and 5 addressing depression symptoms) for adolescent- and parent-report. This set of 11 symptom items achieved sensitivity/specificity values $>.75$, which were comparable to corresponding values for the original RCADS-C/P. Combining adolescent and parent-report improved the identification of anxiety/depression in adolescents compared to using adolescent-report alone. Finally, adding two symptom impact items further improved the sensitivity/specificity of the 11 symptom items, whereas adding suicidal ideation items did not.

Conclusions: The 11 RCADS items accurately discriminated between the community and the clinicreferred sample with anxiety and/or depressive disorders and have the potential to quickly and accurately identify adolescents with these disorders in community settings. 


\section{Introduction}

Anxiety and depressive disorders are the most common mental health disorders in adolescents. The estimated prevalence of anxiety disorders in this age group is around $8 \%$ (Lawrence et al., 2015; Polanczyk et al., 2015; Sadler et al., 2018) and depressive disorders around 5\% (Merikangas et al., 2010). In addition, these disorders often occur simultaneously in adolescents (Axelson \& Birmaher, 2001; Essau, 2008). Anxiety and depressive disorders in adolescents are associated with poor academic, social and health outcomes (Lawrence et al., 2015; Riegler et al., 2017; Sadler et al., 2018) and are key contributors to the global economic burden of disease (Whiteford et al., 2013), emphasising the need for early identification and treatment. However, less than two-thirds of young people and their families access any professional help, and only a minority of young people access specialist mental health support (Johnson et al., 2016; Merikangas et al., 2010; Sadler et al., 2018). Key reasons underlying poor treatment utilisation relate to difficulties identifying common mental health problems and the availability of professional help (Lawrence et al., 2015; Sadler et al., 2018).

Professionals within schools and primary care services are well placed to identify symptoms of anxiety and depression in adolescents at an early stage (Department of Health \& Department of Education, 2017; Siu \& U S Preventive Services Task Force, 2016). The availability of questionnaire tools that are able to accurately identify adolescents with anxiety and depressive disorders could help address barriers related to identification in these settings. However, as practitioners working in these settings face significant time restraints, any identification tools must be brief (i.e. $<15$ items) (Dowdy et al., 2010), easy to use and interpret (e.g. with clear instructions and cut-off scores) (Glover \& Albers, 2007; Myers \& Winters, 2002), and psychometrically adequate (e.g. sensitivity/specificity $>75 \%$ ) (Glover \& Albers, 2007). Brief tools for detecting anxiety and depression in adults, such as the GAD-7 (Spitzer et al., 2006) and the PHQ-9 (Kroenke et al., 2001), provide evidence that brief questionnaires can 
demonstrate good $(>.80)$ sensitivity and specificity in primary care settings. However, these questionnaires were developed for adults, making them less appropriate for use with adolescents (Myers \& Winters, 2002). Brief anxiety questionnaires for children exist (e.g. SCAS-8; Reardon, Spence, Hesse, Shakir, \& Creswell, 2017), but these have only been developed and tested with preadolescent children and do not include depression items, which makes them less suitable for adolescents. Finally, although adolescents generally provide reliable assessments of their mental health, especially emotional disorders (Aebi et al., 2017; Deighton et al., 2014), a combination of adolescent- and parent-report can provide the most reliable and valid information about adolescents' mental health difficulties (Becker et al., 2004; Kuhn et al., 2017). Therefore, a brief identification tool should be available in both, an adolescent-report and parent-report form. To our knowledge, there is currently no questionnaire measure of anxiety and depression symptoms in adolescents meeting the above criteria.

One of the most commonly used measures of anxiety and depressive disorder symptoms across the world is the Revised Children's Anxiety and Depression Scale (RCADS; Chorpita, Yim, Moffitt, Umemoto, \& Francis, 2000). The original 47-item and the shortened 25-item RCADS (Ebesutani et al., 2012) are questionnaire measures of adolescent- and parent-reported symptoms of anxiety and depression in children aged 8 to 18 years. Both RCADS questionnaires demonstrate robust internal consistency in different settings and countries (Piqueras et al., 2017) and are successful in discriminating between clinical samples of young people with a diagnosis of an anxiety disorder or depressive disorder and community samples (Chorpita et al., 2005; Ebesutani et al., 2010, 2017). However, the original RCADS and RCADS-25 are 1) >15 items, and 2) consistent with DSM-IV, rather than DSM-5 diagnostic criteria (American Psychiatric Association, 2013) (e.g. including OCD items), and do not consider either 3) adolescents' suicidal ideation, which is a common symptom of depression in adolescents (Orchard et al., 2017), or 4) the impact or duration of anxiety/depression symptoms 
on adolescents' lives, which may provide a more reliable estimate of emotional disorders than items that only assess the presence of symptoms (Evans et al., 2017; Goodman, 2001).

The purpose of this study was to identify a brief set of RCADS-C/P items to detect anxiety and depressive disorders in young people aged 11 to 17 years. The study involved a community sample $(n=214)$, and a clinic-referred sample $(n=246)$ who met diagnostic criteria for an anxiety disorder $(n=230)$, and/or a depressive disorder $(n=81)$. We identified a subset of anxiety items from a pool of 31 items from the RCADS anxiety subscale that fit with DSM5 anxiety disorder symptoms, and a subset of depression items from 10 RCADS depression subscale items (Chorpita et al., 2000). In addition, we set out to determine 1) if adding items that assess suicidal ideation improves the ability of the depression item subset to discriminate between the community sample and clinic-referred with a depressive disorder diagnosis, 2) if adding items associated with symptom impact and duration improves the ability of the total brief item set to discriminate between the community sample and clinic-referred sample with any anxiety/depressive disorder diagnosis, and 3) whether using a combination of reporters (i.e. adolescent-report and parent-report) provides more accurate identification of adolescents with an anxiety/depressive disorder diagnosis compared to adolescent-report alone. Finally, we evaluated the internal consistency, criterion, convergent and divergent validity, and identified optimal cut-off scores for the final brief item set in terms of 1) anxiety score 2) depression score and 3) total score, and compared these psychometric properties with corresponding properties for the original RCADS and the RCADS-25. 


\section{Method}

\section{Ethical approval}

The community sample was recruited as a part of the wider research project on improving access to treatment for anxiety and depressive disorders in adolescents. This project was approved by the University of Reading Research Ethics Committee (UREC 18/28). Permission to retrospectively use clinical data collected from the clinic-referred sample was obtained from the Berkshire Healthcare NHS Foundation Trust (project number 5491).

\section{Participants}

The demographic and clinical characteristics of the community and clinic-referred samples are outlined in Table 1.

Table 1. The demographic and clinical characteristics of the community and clinic-referred samples

\begin{tabular}{|c|c|c|c|c|c|}
\hline \multirow[b]{2}{*}{ Sample Characteristic } & \multirow[t]{2}{*}{$\begin{array}{l}\text { Community } \\
\text { Sample }\end{array}$} & \multicolumn{3}{|c|}{ Clinic-referred Sample } & \multirow{2}{*}{$\begin{array}{l}\text { Statistic } \\
\text { (clinic-referred vs } \\
\text { community) }\end{array}$} \\
\hline & & Total Sample & $\begin{array}{l}\text { Anxiety } \\
\text { subsample }\end{array}$ & $\begin{array}{l}\text { Depression } \\
\text { subsample }\end{array}$ & \\
\hline$N$ & 214 & 246 & 230 & 81 & \\
\hline Age, Mean $(S D)$ & $\begin{array}{l}13.63 \\
(.75)\end{array}$ & $\begin{array}{l}14.33 \\
(1.73)\end{array}$ & $14.25(1.72)$ & $15.11(1.36)$ & $\begin{array}{l}t(458)=4.313 \\
p<.01, d=.40\end{array}$ \\
\hline \multicolumn{6}{|l|}{ Gender } \\
\hline Females, $n(\%)$ & $123(57.4 \%)$ & $189(76.8 \%)$ & $177(77.0 \%)$ & $64(79.0 \%)$ & $\begin{array}{l}\chi^{2}(1)=18.764 \\
p<.01, V=.20\end{array}$ \\
\hline \multicolumn{6}{|l|}{ Ethnicity } \\
\hline White-British, $n(\%)$ & $172(80.8 \%)$ & $170(86.3 \%)^{\mathrm{a}}$ & $159(85.9 \%)^{\mathrm{b}}$ & $55(85.9 \%)^{\mathrm{c}}$ & $\begin{array}{l}\chi^{2}(1)=1.890 \\
p=.169\end{array}$ \\
\hline \multicolumn{6}{|l|}{ Family Socioeconomic status } \\
\hline Higher/professional ${ }^{\mathrm{d}}, n(\%)$ & $100(46.7 \%)$ & $98(50.5 \%)^{\mathrm{f}}$ & $92(51.1 \%)^{\mathrm{g}}$ & $34(52.3 \%)^{\mathrm{h}}$ & $\begin{array}{l}\chi^{2}(1)=2.258 \\
p=.323\end{array}$ \\
\hline \multicolumn{6}{|l|}{ Parent reporter } \\
\hline Mother, $n(\%)$ & $186(86.9 \%)$ & $204(88.7 \%)^{\mathrm{i}}$ & $190(88.4 \%)^{\mathrm{j}}$ & $64(85.3 \%)^{\mathrm{k}}$ & \\
\hline \multicolumn{6}{|l|}{$\begin{array}{l}\text { Anxiety/depressive disorder } \\
\text { diagnosis }{ }^{\mathrm{e}}, n(\%)\end{array}$} \\
\hline Social Ánxiety Disorder & - & $171(69.5 \%)$ & $171(74.3 \%)$ & $56(69.1 \%)$ & \\
\hline Generalised Anxiety Disorder & - & $156(63.4 \%)$ & $156(67.8 \%)$ & $44(54.3 \%)$ & \\
\hline Major Depressive Disorder & - & $73(29.7 \%)$ & $60(26.1 \%)$ & $73(90.1 \%)$ & \\
\hline Specific Phobia & - & $52(21.1 \%)$ & $52(22.6 \%)$ & $9(11.1 \%)$ & \\
\hline Agoraphobia & - & $27(11.0 \%)$ & $27(11.7 \%)$ & $7(8.6 \%)$ & \\
\hline Separation Anxiety Disorder & - & $21(8.5 \%)$ & $15(6.5 \%)$ & $6(7.4 \%)$ & \\
\hline Panic Disorder & - & $27(11.0 \%)$ & $27(11.7 \%)$ & $6(7.4 \%)$ & \\
\hline
\end{tabular}




\begin{tabular}{|c|c|c|c|c|}
\hline Dysthymia & - & $16(6.5 \%)$ & $13(5.7 \%)$ & $16(19.8 \%)$ \\
\hline Illness Anxiety Disorder & - & $3(1.2 \%)$ & $3(1.3 \%)$ & $0(0 \%)$ \\
\hline $\begin{array}{r}\text { Unspecified Depressive } \\
\text { Disorder }\end{array}$ & - & $2(.8 \%)$ & $1(.4 \%)$ & $2(2.5 \%)$ \\
\hline Unspecified Anxiety Disorder & - & $2(.8 \%)$ & $2(.9 \%)$ & $0(0 \%)$ \\
\hline $\begin{array}{l}\text { Primary diagnosis CSR, Mean } \\
(S D)\end{array}$ & - & $5.96(1.00)$ & $5.94(1.04$ & $6.46(.87)$ \\
\hline $\begin{array}{l}\text { Any Anxiety disorder diagnosis, } \\
n(\%)\end{array}$ & - & $230(93.5 \%)$ & $230(100 \%)$ & $65(80.2 \%)$ \\
\hline $\begin{array}{l}\text { Any Depressive disorder } \\
\text { diagnosis, } n(\%)\end{array}$ & - & $81(32.9 \%)$ & $65(28.3 \%)$ & $81(100 \%)$ \\
\hline $\begin{array}{l}\text { Non-anxiety/depressive disorder } \\
\text { diagnosis (OCD, ODD, PTSD, } \\
\text { ADD, ADHD), } n(\%)\end{array}$ & - & $26(10.6 \%)$ & $26(11.3 \%)$ & $11(13.6 \%)$ \\
\hline
\end{tabular}

\section{Community Sample}

In total, 1,165 students were screened for anxiety and depression (see Measures section) through two secondary schools in Berkshire, England. Only adolescents for whom both adolescent- and parent-report questionnaire measures were provided were included in this study $(n=214)$. Nearly $70 \%$ of adolescents in the community sample were aged between 11 and 14 (classified as 'younger adolescents') and 30.8\% were aged between 15 and 18 (classified as 'older adolescents').

\section{Clinic-referred Sample}

The clinic-referred sample was recruited through the Anxiety and Depression in Young People (AnDY) Research Clinic, based at the University of Reading and funded by East Berkshire and Berkshire West Clinical Commissioning Groups. The clinic-referred sample $(n=246)$ included young people aged between 11 and 17, who took part in the standardised diagnostic assessment (see Measures section), and met criteria for a current DSM-5 anxiety and/or depressive disorder anywhere in their diagnostic profile (i.e. primary and secondary diagnoses). A total of 246 adolescents met the study inclusion criteria, of whom 230 met the diagnostic criteria for an anxiety disorder (clinic-referred anxiety subsample) and 81 met the diagnostic criteria for a 
depressive disorder (clinic-referred depression subsample) anywhere in their diagnostic profile. In the total clinic-referred sample, $48 \%$ of adolescents were 'younger adolescents' and $52 \%$ were 'older adolescents'.

\section{Procedure}

\section{Community Sample}

We approached 31 state secondary schools in Berkshire, Buckinghamshire, London, North England and Oxfordshire from September to November 2018. Invited schools had no academic entry criteria and were not taking part in other University research projects. Two large mixed state schools (both in Berkshire) agreed to take part. Participating schools distributed information leaflets and opt-out consent forms to 1,706 parents/carers. After two weeks, the lead researcher (JR) administered paper forms of the adolescent-report questionnaires with students from Year 7 to Year 13, whose parents/carers had not opted out (97.7\%). Of 1,237 students invited to take part, $94.2 \%$ provided consent/assent and completed the questionnaires. School staff and the researcher oversaw questionnaire completion in classrooms and ensured that responses were confidential. Adolescent background information (e.g. date of birth and gender) was collected from school records at the same time. Where questionnaire responses indicated any risk or raised concerns about the young person's safety, this was reported to the schools' safeguarding teams immediately. Both schools then distributed questionnaires to parents/carers, usually by emailing a link to online versions of the questionnaires, and in some cases they also sent paper copies. Up to five reminders within a five-week time frame were then sent to young people's parents/carers to encourage them to complete the questionnaires. Of 1,165 students who completed self-report questionnaires, $214(18.7 \%)$ parents/carers completed the parent questionnaire as well. To help encourage parent/carer participation, schools were reimbursed $£ 3$ for each returned paired (adolescent-parent) questionnaire set. 


\section{Clinic-referred Sample}

Adolescents in the clinic-referred sample were assessed with standardised diagnostic assessments (ADIS-C/P and K-SADS) from January 2017 to June 2019 in the AnDY Research Clinic, University of Reading. At the point of the initial assessment, each young person and their parent completed the RCADS-C/P questionnaire measures. The routine initial assessment questionnaire pack has included symptom impact and duration questions since May 2017, and the Mood and Feelings Questionnaire (MFQ) since March 2018.

\section{Measures}

\section{Questionnaires}

Revised Child Anxiety and Depression Scale, Child and Parent Versions (RCADS-C/P; Chorpita, Yim, Moffitt, Umemoto, \& Francis, 2000). The RCADS is a 47-item questionnaire measure of symptoms of anxiety and low mood in young people, aged from 8 to 18 years. It was developed as an adaptation of the Spence Children's Anxiety Scale (SCAS; Spence, 1997, 1998) with additional items to assess symptoms of depression. The questionnaire consists of six subscales: separation anxiety disorder (SAD), social phobia (SP), obsessive-compulsive disorder (OCD), panic disorder (PD), generalised anxiety disorder (GAD), and major depressive disorder (MDD). Respondents rate how often each item applies to them/their child, using a 4-point scale from 0 ('never') to 3 ('always'). The RCADS is available in adolescentand parent-report form and it takes between 10 and 15 minutes to complete (Chorpita et al., 2000). In the current study, the RCADS anxiety scale (37 items), depression scale (10 items) and total scale (47 items) scores were calculated by summing responses to corresponding items. As OCD is no longer classified as an anxiety disorder in the DSM-5 (American Psychiatric 
Association, 2013) these six items were not considered for inclusion in the final screening items, and were excluded from the individual item analyses.

Symptom impact and duration questions. Participants completed an additional seven questions designed for this study to measure the duration of anxiety/depression symptoms $(0=$ 'less than a month', 1 = ' $1-5$ months', $2=$ ' $6-12$ months', 3 = 'over a year') and the degree of interference with activities at home/school/friends/outside the school caused by any endorsed symptoms $(0=$ 'not at all', $1=$ 'only a little', $2=$ 'quite a lot', $3=$ 'a great deal' $)$. The content of these questions was informed by other similar questionnaires, including the Strengths and Difficulties Questionnaire (SDQ)-Impact Supplement (Goodman, 1999). The individual item score (from 0 to 3 ) was calculated for each symptom duration/impact item.

Moods and Feelings Questionnaire (MFQ-C/P; Angold \& Costello, 1987). The MFQ is a 33item (34-item for parent version) screening tool for depression in children and young people, aged between 6 and 17. Respondents are asked to report how they have been feeling or acting in the past two weeks. For each item, they can respond with 'not true' (0), 'sometimes' (1) or 'true' (2). The MFQ total score is calculated by summing participants' responses to all items. In the present study, we used the MFQ total score and individual item scores for four items assessing young people's suicidal ideation ('thought about killing self', 'thought about death or dying', 'thought family would be better off without self' and 'thought life was not worth living'). The utility of these four items to accurately identify adolescents with suicidal ideation has been established in previous research (Hammerton et al., 2014). For the current study, participants' responses to each of these four items were transformed to a scale from 0 to 3 using linear transformation (Jonge et al., 2014) to match the RCADS response scale. These transformed individual item scores $(0,1.5$ or 3$)$ were used in individual item analyses. Prior to 
transforming individual items, MFQ total scores were calculated by summing participants' original responses ( 0 to 2$)$ to all MFQ items.

\section{Diagnostic Interviews}

The following diagnostic interviews were administered with the clinic-referred sample to assess the presence of an anxiety and/or depressive disorder in young people. Assessors were psychology graduates specifically trained to deliver the diagnostic assessments. All assessments were discussed with an experienced member of the assessment team to agree on a consensus diagnosis. Inter-rater reliability for the presence of an anxiety diagnosis on the ADIS-C/P $\kappa=1.00$ and CSR ICC $=.93$, and of a K-SADS depression diagnoses was $\kappa=1.00$.

Anxiety Disorder Interview Schedule - Child-Parent Version (ADIS-IV-C/P; Albano \& Silverman, 1996). The ADIS-IV-C/P is based on the DSM-IV-TR (American Psychiatric Association, 2000) and consists of two semi-structured interviews (separately with the adolescent and their parent) designed to assess anxiety and other disorders in children and adolescents aged 7-16. In the present study, the anxiety sections of the ADIS-IV-C/P were used to determine whether the adolescent met diagnostic criteria for any anxiety disorder. Minor adaptations to the interview schedule were made so the diagnoses were assigned based on the DSM-5. If the adolescent met symptom criteria for a diagnosis, based on either their report or that of their parent, then the clinician would assign a Clinician Severity Rating (CSR), ranging from 0 to 8; a CSR of 4 or more would indicate that the young person met criteria for diagnosis. The diagnosis with the highest CSR was considered to be the primary diagnosis. Studies using the ADIS-IV-C/P provide strong empirical support for its good test-retest reliability (Silverman et al., 2001) and high levels of inter-rater agreement (Lyneham et al., 2007). The concurrent validity of the diagnostic tool is especially good for the anxiety section (Wood, Piacentini, 
Bergman, McCracken, \& Barrios, 2002). As such, ADIS-IV-C/P has been considered as a 'gold standard' measure of anxiety disorders in young people's clinical research.

Kiddie Schedule for Affective Disorders and Schizophrenia - Present and Lifetime Version (KSADS-PL DSM-5; Kaufman et al., 2016).The K-SADS-PL is a semi-structured integrated parent and child interview for affective disorders and schizophrenia. In the current study, a DSM-5 (APA, 1994) version of the K-SADS was used. The administration of the interview lasts approximately 30 minutes with each respondent, and young people and caregivers are interviewed separately. Research studies support adequate psychometric characteristics of the K-SADS-PL with high interrater and test-retest reliability and concurrent validity (Kaufman et al., 1997). The K-SADS-PL is more widely used in clinical research focused on depression than the ADIS-C/P (Spence, 2018), and in the present study, the depression and mania sections of the K-SADS-PL child and parent interview were used to determine the presence/absence of depressive disorders in adolescents. As per a standard procedure, the diagnosis of depressive disorder was assigned based on adolescent- and parent report combined. In addition, CSR scores were assigned in a similar way as the ADIS-C/P to provide a comparable estimate of the symptom severity/interference.

\section{Data Analytical Strategy}

\section{Sample Size Calculation}

We computed an a priori power analysis for a Receiver Operating Characteristics (ROC) curve using R, package 'pROC' (Robin et al., 2011). Power analysis determined a minimum sample size of 30 participants in each group included in ROC analyses (i.e. participants from the community sample, clinic-referred anxiety subsample and clinic-referred depression 
subsample) to achieve a sufficient power of .80 with an Area Under the Curve (AUC) of .70 and $\alpha=.05$.

The following procedure was used to identify items for inclusion in the brief screen for anxiety and depression (adolescent- and parent-report versions):

\section{Symptom item reduction}

The pool of potential anxiety items consisted of 31 anxiety items from the RCADS anxiety subscale (i.e. all anxiety items excluding the OCD items), and the pool of potential depression items consisted of 10 depression items from the RCADS depression subscale. To examine the functioning of potential anxiety items, we combined the community sample $(n=214)$ and the clinic-referred anxiety subsample $(n=230)$. Similarly, we examined the functioning of potential depression items by combining the community sample $(n=214)$ with the clinicreferred depression subsample $(n=81)$. We performed the following analyses to reduce the pool of eligible items for adolescent- and parent-report separately: 1) we examined item-total score correlations (anxiety: item-RCADS-C/P anxiety total correlation; depression: itemRCADS-C/P depression total correlation), 2) we calculated the item-discrimination indices using point biserial correlation coefficient (anxiety: item-presence of an anxiety disorder correlation, depression: item-presence of a depressive disorder correlation). In addition, we calculated partial correlations by controlling item-discrimination indices for participants' gender (female/male) and age group ('early' [11-14 years] and 'late' [15-17 years] adolescence), to ensure that only items that performed similarly across both genders/age groups were selected, 3) we investigated the number of missing values. Items with either high $(>.70)$ item-total score correlation or high $(>.30)$ item-discrimination index, and with a low $(<10 \%)$ proportion of missing values were further considered. 


\section{Examining the functioning of alternative subsets of RCADS items}

First, we created alternative adolescent-report anxiety/depression brief item sets by removing eligible items with the lowest item-discrimination indices one by one. We also considered the content of the items to minimise overlapping content among items, and removed items where the meaning was very similar to an alternative item. We then used ROC curve analyses to compare the ability of 1) alternative subsets of RCADS anxiety items to discriminate between the community sample and the clinic-referred anxiety subsample, and 2) alternative subsets of RCADS depression items to discriminate between the community sample and the clinicreferred depression subsample. Following previous research using similar methodology (e.g. Reardon, Spence, Hesse, Shakir, \& Creswell, 2017) we set a threshold value of AUC = .7. As the item sets were identified for screening purposes, sensitivity of the cut-off score was prioritised over specificity (Kraemer, 1992). The cut-off scores with sensitivity of $>.8$ and specificity of $>.7$ were calculated. Where sensitivity/specificity $>.8 / .7$ were not achievable, cut-off scores with sensitivity/specificity $>.7 / .7$ or $>.7 / .6$ were considered. We repeated the ROC analyses across different gender (female/male) and age ('early' [11-14 years] and 'late' [15-17 years] adolescence) groups to identify item sets that performed similarly across gender/age troups.

Once we had identified the brief set of adolescent-report anxiety items and depression items, we then examined the functioning of alternative parent-report anxiety/depression item combinations using the same ROC analyses. Given the practical utility of including common items across adolescent- and parent-report, firstly we examined the functioning of parent-report anxiety/depression brief item sets that included the same items as the final combinations for adolescent-report. Then, we created alternative parent-report anxiety/depression item combinations, using the same procedure as we used for adolescent-report (i.e. by removing eligible parent-report items with the lowest item-discrimination indices one by one) to identify 
the 'optimal' set of parent-report anxiety/depression items, and compared these to parent-report item sets that included the same items as those identified for adolescent-report.

\section{Examining the functioning of items assessing suicidal ideation and symptom}

\section{impact and duration items and whether adding them improves the measures}

We calculated item-discrimination indices using point biserial correlation coefficients for the

1) items assessing young people's suicidal ideation and the presence of depressive disorder diagnosis, and 2) symptom impact and duration items and the presence of any anxiety/depressive disorder. Items with a high $(>.30)$ item-discrimination index, and a low $(<$ $10 \%$ ) proportion of missing values were further considered. Similar to the process of identifying brief subsets of symptom items, we then used ROC analyses to identify items assessing 1) suicidal ideation and 2) symptom impact/duration, to use together with the brief sets of symptom items. Suicidal ideation/impact and duration items with the lowest itemdiscrimination indices were removed one by one. We then examined the functioning of parentreport brief depression/total symptom item sets together with the same suidical ideation/symptom impact and duration items that were identified in adolescent-report. The same procedure (i.e. by removing items with the lowest item-discrimination indices one by one) was then repeated for the parent-report to identify the optimal combinations of suicidal ideation/impact and duration items to use together with the brief depression/total symptom item sets for parent-report. We then compared these to using the same suicidal ideation/symptom impact and duration items as the adolescent-report. Finally, we used a series of logistic regressions to establish whether adding the identified combination of 1) suicidal ideation items improved the ability of the brief depression screen to discriminate between adolescents in the community and clinic-referred depression subsample, and 2) symptom impact and duration items improved the ability of the brief total screen to discriminate between adolescents in the 
community and clinic-referred sample. Independent variables were added in logistic regression model one by one, starting with the brief depression/total symptoms item set.

\section{Combining adolescent-report and parent-report}

We examined whether combining adolescent- and parent-report improved the identification of adolescents with an anxiety/depressive disorder diagnosis, compared to using adolescent-report alone. We performed logistic regressions with the adolescent group (i.e. community sample and clinic-referred anxiety/depression subsample) as the dependent variable and different combination of participants' responses (i.e. adolescent-report and adolescent-report + parentreport) as independent variables. Participants' responses were added to the regression models one by one, starting with the adolescent-report.

\section{Psychometric evaluation of the brief set of RCADS anxiety and depression item} sets and comparison with the original RCADS and the RCADS-25

Using the brief set of RCADS items, we calculated adolescent- and parent-report brief anxiety, depression and total scores for all participants by summing their responses to corresponding items. We then calculated the following psychometric properties of the brief adolescent- and parent-report anxiety/depression/total scores, and compared these with the corresponding properties of the original RCADS and RCADS-25 anxiety/depression/total scores: internal consistency, convergent, discriminant, and criterion validity. Internal consistency was calculated using McDonald's omega coefficients. We assessed convergent validity using Pearson correlation coefficients between the brief depression score/original RCADS depression score/RCADS-25 depression score and MFQ total score, and divergent validity using Pearson correlation coefficients between the brief anxiety score/original RCADS anxiety score/RCADS-25 anxiety score and MFQ total scores. Criterion validity of the brief anxiety/depression/total score, and original RCADS/RCADS-25 anxiety/depression/total scores was assessed using ROC curve analyses following procedures described previously, to 
identify the AUC and optimal cut-off scores and their corresponding sensitivity/specificity values for the optimal cut-off scores. ROC curve analyses were repeated for separate gender and age groups.

\section{Missing data}

Across all items, missing responses were $<4 \%$ in the community sample and $<14 \%$ in the clinic-referred sample, with the exception of MFQ-C/P and symptom impact items and duration items in the clinic referred sample (29-43\%), which as detailed above were only introduced into the routine initial assessment in May 2017 (symptom impact and duration items) and March 2018 (MFQ-C/P). Following previous research (e.g. Donnelly et al., 2019), we handled all the missing values as pairwise missing. We performed sensitivity analyses to confirm that the clinic-referred sample of adolescents without MFQ-C/P responses was not significantly different from the clinic-referred sample of adolescents who had fully completed the questionnaires. Mean RCADS-C/P anxiety and depression scores were calculated for participants in the clinic-referred sample who had fully completed the questionnaires and for the participants that had only completed RCADS-C/P. Means were compared using independent samples $t$-tests. In addition, we calculated Pearsons's correlation coefficients between RCADS anxiety and depression subscales for participants with fully and partially completed questionnaires. No significant differences were found between the two groups of adolescents, confirming that these data can be treated as missing completely at random (MCAR).

Due to the large sample sizes $(>200)$, we used a conservative $p$-value of 0.01 . All the analyses were performed using R version 3.6.1 (R Core Team, 2019) packages 'cvAUC' (LeDell et al., 2014), 'pROC' (Robin et al., 2011), 'psych' (Revelle, 2018) and 'userfriendlyscience' (Peters, 2018). 


\section{Results}

\section{Symptom item reduction}

Item-anxiety/depression total correlations and item-discrimination indices (total; controlled for adolescents' gender and age) for adolescent-report are displayed in Table 2. Corresponding item-total correlations and item-discrimination indices for parent-report are provided in Appendix A.

Table 2. Rank-ordered item-total correlations and item-discrimination indices for the RCADSC items

\begin{tabular}{|c|c|c|c|c|c|}
\hline \multirow[b]{2}{*}{ Item number } & \multirow[b]{2}{*}{ Item (RCADS Subscale) } & \multirow[b]{2}{*}{$\begin{array}{l}\text { Item- } \\
\text { total }\end{array}$} & \multicolumn{3}{|c|}{$\begin{array}{l}\text { Item-anxiety/depression } \\
\text { diagnosis correlation }\end{array}$} \\
\hline & & & Total & $\begin{array}{l}\text { Control } \\
\text { led for } \\
\text { Gender }\end{array}$ & $\begin{array}{l}\text { Control } \\
\text { led for } \\
\text { age }\end{array}$ \\
\hline & Anxiety items & & & & \\
\hline RCADS35 $5^{\mathrm{a}, \mathrm{b}}$ & $\begin{array}{l}\text { I worry about what is going to happen } \\
\text { (GAD) }\end{array}$ & $.76^{*}$ & $.38^{*}$ & $.35^{*}$ & $.37 *$ \\
\hline $\operatorname{RCADS} 28^{\mathrm{a}, \mathrm{b}}$ & When I have a problem, I feel shaky (PD) & $.72 *$ & $.32 *$ & $.28 *$ & $.31^{*}$ \\
\hline RCADS41 $1^{\mathrm{a}, \mathrm{b}}$ & $\begin{array}{l}\text { I worry that I will suddenly get a scared } \\
\text { feeling when there is nothing to be afraid } \\
\text { of (PD) }\end{array}$ & $.71 *$ & $.31 *$ & $.27 *$ & $.29 *$ \\
\hline $\operatorname{RCADS} 22^{\mathrm{a}, \mathrm{b}}$ & $\begin{array}{l}\text { I worry that bad things will happen to me } \\
\text { (GAD) }\end{array}$ & $.71 *$ & $.26^{*}$ & $.24^{*}$ & $.27^{*}$ \\
\hline RCADS24, & $\begin{array}{l}\text { When I have a problem, my heart beats } \\
\text { really fast (PD) }\end{array}$ & $.71 *$ & $.36^{*}$ & $.32 *$ & $.35^{*}$ \\
\hline $\operatorname{RCADS} 20^{\mathrm{a}, \mathrm{b}}$ & I worry I might look foolish (SOC) & $.71^{*}$ & $.35^{*}$ & $.31 *$ & $.33 *$ \\
\hline RCADS34, & $\begin{array}{l}\text { All of a sudden I feel really scared for no } \\
\text { reason at all (PD) }\end{array}$ & $.71^{*}$ & $.37 *$ & $.33^{*}$ & $.36^{*}$ \\
\hline RCADS $1^{\mathrm{a}, \mathrm{b}}$ & I worry about things (GAD) & $.71^{*}$ & $.31 *$ & $.28^{*}$ & $.30 *$ \\
\hline 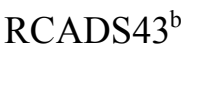 & $\begin{array}{l}\text { I feel afraid that I will make a fool of } \\
\text { myself in front of people (SOC) }\end{array}$ & $.68^{*}$ & $.27^{*}$ & $.24^{*}$ & $.26^{*}$ \\
\hline RCADS $14^{\mathrm{b}}$ & $\begin{array}{l}\text { I suddenly feel as if I can't breathe when } \\
\text { there is no reason for this (PD) }\end{array}$ & $.68^{*}$ & $.27^{*}$ & $.24^{*}$ & $.26^{*}$ \\
\hline $\operatorname{RCADS} 27^{\mathrm{b}}$ & $\begin{array}{l}\text { I worry that something bad will happen to } \\
\text { me (GAD) }\end{array}$ & $.68^{*}$ & $.25^{*}$ & $.23 *$ & $.25^{*}$ \\
\hline $\operatorname{RCADS} 30^{\mathrm{b}}$ & I worry about making mistakes (SOC) & $.67^{*}$ & $.25^{*}$ & $.22 *$ & $.24^{*}$ \\
\hline $\operatorname{RCADS} 12^{\mathrm{b}}$ & $\begin{array}{l}\text { I worry that I will do badly at my school } \\
\text { work (SOC) }\end{array}$ & $.65^{*}$ & $.26^{*}$ & $.22 *$ & $.24 *$ \\
\hline RCADS32 & $\begin{array}{l}\text { I worry what other people think of me } \\
\text { (SOC) }\end{array}$ & $.64^{*}$ & $.28^{*}$ & $.24 *$ & $.27^{*}$ \\
\hline $\mathrm{RCADS}^{\mathrm{b}}$ & $\begin{array}{l}\text { I feel scared when I have to take a test } \\
\text { (SOC) }\end{array}$ & $.64^{*}$ & $.26^{*}$ & $.22 *$ & $.24 *$ \\
\hline RCADS39 $9^{\mathrm{b}}$ & $\begin{array}{l}\text { My heart suddenly starts to beat too } \\
\text { quickly for no reason (PD) }\end{array}$ & $.64^{*}$ & $.26^{*}$ & $.23 *$ & $.25^{*}$ \\
\hline
\end{tabular}




\begin{tabular}{|c|c|c|c|c|c|}
\hline RCADS26 & $\begin{array}{l}\text { I suddenly start to tremble or shake when } \\
\text { there is no reason for this (PD) }\end{array}$ & $.63^{*}$ & $.27^{*}$ & $.24 *$ & $.26^{*}$ \\
\hline RCADS $8^{b}$ & $\begin{array}{l}\text { I feel worried when I think someone is } \\
\text { angry with me (SOC) }\end{array}$ & $.62 *$ & $.26^{*}$ & $.22 *$ & $.25 *$ \\
\hline $\mathrm{RCADS}^{\mathrm{a}, \mathrm{b}}$ & $\begin{array}{l}\text { When I have a problem, I get a funny } \\
\text { feeling in my stomach (PD) }\end{array}$ & $.61 *$ & $.30^{*}$ & $.26^{*}$ & $.29 *$ \\
\hline $\operatorname{RCADS} 18^{\mathrm{a}, \mathrm{b}}$ & $\begin{array}{l}\text { I have trouble going to school in the } \\
\text { mornings because I feel nervous or afraid } \\
\text { (SEP) }\end{array}$ & $.61 *$ & $.47^{*}$ & $.45^{*}$ & $.47 *$ \\
\hline $\mathrm{RCADS}^{\mathrm{b}}$ & $\begin{array}{l}\text { I worry when I think I have done poorly } \\
\text { at something (SOC) }\end{array}$ & $.61^{*}$ & $.20^{*}$ & $.17^{*}$ & $.17^{*}$ \\
\hline RCADS45 $5^{\mathrm{a}, \mathrm{b}}$ & I worry when I go to bed at night (SEP) & $.61^{*}$ & $.41^{*}$ & $.38^{*}$ & $.41 *$ \\
\hline $\operatorname{RCADS} 33^{\mathrm{a}, \mathrm{b}}$ & $\begin{array}{l}\text { I am afraid of being in crowded places } \\
\text { (like shopping centres, the cinema, buses, } \\
\text { busy playgrounds) (SEP) }\end{array}$ & $.60^{*}$ & $.31 *$ & $.28^{*}$ & $.30 *$ \\
\hline RCADS36 & $\begin{array}{l}\text { I suddenly become dizzy or faint when } \\
\text { there is no reason for this (PD) }\end{array}$ & $.55^{*}$ & $.20^{*}$ & $.16^{*}$ & $.19 *$ \\
\hline RCADS13 & $\begin{array}{l}\text { I worry that something awful will happen } \\
\text { to someone in my family (GAD) }\end{array}$ & $.54 *$ & .07 & .02 & .07 \\
\hline RCADS38 ${ }^{\mathrm{b}}$ & $\begin{array}{l}\text { I feel afraid if I have to talk in front of my } \\
\text { class (SOC) }\end{array}$ & $.53 *$ & $.22 *$ & $.18^{*}$ & $.21 *$ \\
\hline RCADS37 & I think about death (GAD) & $.51^{*}$ & $.14^{*}$ & $.12 *$ & $.14 *$ \\
\hline RCADS46 ${ }^{\mathrm{b}}$ & $\begin{array}{l}\text { I would feel scared if I had to stay away } \\
\text { from home overnight (SEP) }\end{array}$ & $.48^{*}$ & $.26^{*}$ & $.24^{*}$ & $.28 *$ \\
\hline RCADS9 & $\begin{array}{l}\text { I worry about being away from my } \\
\text { parents (SEP) }\end{array}$ & $.48^{*}$ & .10 & .07 & .12 \\
\hline RCADS5 & $\begin{array}{l}\text { I would feel afraid of being on my own at } \\
\text { home (SEP) }\end{array}$ & $.47^{*}$ & $.25^{*}$ & $.22 *$ & $.26^{*}$ \\
\hline \multirow[t]{2}{*}{ RCADS17 } & $\begin{array}{l}\text { I feel scared if I have to sleep on my own } \\
\text { (SEP) }\end{array}$ & $.41^{*}$ & $.18^{*}$ & $.15^{*}$ & $.20 *$ \\
\hline & Depression items & & & & \\
\hline RCADS29 $9^{\mathrm{a}, \mathrm{b}}$ & I feel worthless (MDD) & $.81 *$ & $.40^{*}$ & $.39 *$ & $.38 *$ \\
\hline RCADS $19^{a, b}$ & I have no energy for things (MDD) & $.80^{*}$ & $.44 *$ & $.43^{*}$ & $.40^{*}$ \\
\hline RCADS $40^{\mathrm{a}, \mathrm{b}}$ & I feel like I don't want to move (MDD) & $.79 *$ & $.35^{*}$ & $.33^{*}$ & $.32 *$ \\
\hline $\operatorname{RCADS}^{\mathrm{a}, \mathrm{b}}$ & I feel sad or empty (MDD) & $.77^{*}$ & $.40^{*}$ & $.39 *$ & $.36^{*}$ \\
\hline $\operatorname{RCADS} 21^{\mathrm{a}, \mathrm{b}}$ & I am tired a lot (MDD) & $.75^{*}$ & $.40^{*}$ & $.39^{*}$ & $.35 *$ \\
\hline $\operatorname{RCADS} 47^{\mathrm{a}}$ & I feel restless (MDD) & $.75^{*}$ & $.31^{*}$ & $.30^{*}$ & $.28 *$ \\
\hline RCADS6 $6^{\mathrm{a}, \mathrm{b}}$ & Nothing is much fun anymore (MDD) & $.73 *$ & $.41^{*}$ & $.41^{*}$ & $.38 *$ \\
\hline $\operatorname{RCADS} 25^{\mathrm{a}, \mathrm{b}}$ & I cannot think clearly (MDD) & $.73 *$ & $.29 *$ & $.28 *$ & $.27 *$ \\
\hline RCADS $11^{b}$ & I have trouble sleeping (MDD) & $.64 *$ & $.28 *$ & $.26^{*}$ & $.28 *$ \\
\hline $\operatorname{RCADS} 15^{\mathrm{a}}$ & I have problems with my appetite (MDD) & $.64 *$ & $.31 *$ & $.30 *$ & $.29 *$ \\
\hline
\end{tabular}

Note. $\mathrm{GAD}=$ generalised anxiety disorder, $\mathrm{PD}=$ panic disorder, $\mathrm{SOC}=$ social anxiety disorder, $\mathrm{SEP}=$ separation anxiety disorder, atem retained in the reduced pool of eligible adolescent-report anxiety items, ${ }^{\mathrm{b}}$ Item retained in the reduced pool of eligible parent-report anxiety items, ${ }^{*} p<.01$. 


\section{Anxiety items}

All RCADS-C/P anxiety symptom items were significantly $(p<.01)$ correlated with the original RCADS-C/P anxiety total score, with correlations ranging from .41 to .76 for adolescent-report items and from .43 to .81 for parent-report items. With the exception of item 13 ('I worry that something awful will happen to someone in my family') and item 9 ('I worry about being away from my parents'), all RCADS-C anxiety items discriminated between the clinic-referred anxiety subsample and the community sample $(p<.01)$, and this was maintained after controlling for adolescents' gender and age. All RCADS-P anxiety items were ) associated with adolescents' group (community versus clinic-referred anxiety subsample; $p<.01$ ), and again, these associations were retained after controlling for adolescents' gender and age. Twelve RCADS-C anxiety symptom items had an item-total correlation $\geq .7$ and/or item-discrimination index $\geq .3$ and were therefore further considered for inclusion the brief RCADS anxiety item set. Notably, 24 RCADS-P items met the same criteria, including parent-report versions of all 12 retained RCADS-C items.

\section{Depression items}

Correlations between the RCADS-C/P depression items and the original RCADS-C/P depression total score were moderate to large (ranging from .60 to .81 for adolescent-report and from .49 to .83 for parent-report, $p<.01)$. All adolescent and parent-report depression symptom items discriminated between the community and clinic-referred depression subsample, with item discrimination indices ranging from .16 to .40 for adolescent-report and .25 to .42 for parent-report. As with the anxiety items, these associations remained significant $(p<.01)$ for both adolescent- and parent-report after controlling for adolescent gender and age. Nine adolescent-report and 8 parent-report depression symptom items had an item-total correlation $\geq .7$ and/or item-discrimination index $\geq .3$ and were retained for further consideration, including seven common items across the reduced adolescent/parent-report item pool. 


\section{Alternative numbers of items}

Findings from a series of ROC curve analyses examining the functioning of alternative subsets of adolescent-report anxiety items ( $\leq 12$ items) and depression items ( $\leq 9$ items) are displayed in Appendix B. ${ }^{1}$

\section{Anxiety item selection}

The final subset of adolescent-report RCADS anxiety items consisted of six anxiety symptom items (RCADS-C 18, 45, 35, 34, 24, 20) assessing symptoms associated with separation anxiety disorder, generalised anxiety disorder, panic disorder and social anxiety disorder. The set of 6items identified adolescents in the clinic-referred anxiety subsample with an AUC of .81 and using an optimal cut-off score of 7.5, achieved sensitivity/specificity values of .77/.74. Parentreport on the same 6 anxiety items achieved an AUC of .86, and the optimal cut-off of 5.5 was associated with sensitivity/specificity values of $.80 / .70$.

\section{Depression item selection}

The final subset of adolescent-report RCADS depression items consisted of five depressive symptoms items (RCADS 19, 6, 29, 2, 21), reflecting a lack of energy/fatigue, anhedonia, feelings of worthlessness and depressed mood. The 5 items identified adolescents in the clinicreferred depression subsample with an AUC of .89 and an optimal cut-off score of 9.25 was associated with sensitivity/specificity values of $.83 / .79$. Parent-report using the same 5 depression items as identified for adolescents achieved an AUC of .87 and an optimal cut-off score of 6.75 , with sensitivity/specificity values of $.90 / .77$ respectively.

\footnotetext{
${ }^{1}$ We used the same procedure to examine the functioning of alternative parent-report anxiety ( $\leq 24$ items) and depression $(\leq 9$ items) subsets. The ROC curve analyses confirmed that the brief parent-report anxiety item set achieved an AUC of .84 which was not significantly different $(p=.16)$ from the parent-report anxiety set that included the same items identified for adolescent-report of anxiety. The brief parent-report depression item set included the same five items as for adolescent-report of depression.
} 


\section{Examining the functioning of items assessing risk of suicide/self-harm and symptom impact and duration}

Appendix C displays 1) the rank ordered item discrimination indices for items assessing suicidal ideation and symptom impact and duration, 2) findings from the ROC curve analyses using alternative combinations of suidical ideation/impact and duration items together with the 5 RCADS depression items/11 RCADS items and 3) a series of binary logistic regressions using either adolescent-report or parent-report, with and without additional items assessing suicidal ideation/impact/duration.

Adding one item assessing suicidal ideation (MFQ 19-C/P 'I/My child thought about killing myself/himself/herself') to the 5 RCADS depression items achieved AUC values of $>$ .80 , and sensitivity/specificity values of 83/.79 (adolescent-report) and .90/.77 (parent-report). However, the results of the binary logistic regressions illustrated that this item did not make a significant contribution to the identification of adolescents in the clinic-referred depression sample (adolescent-report: $\chi^{2}(1)=6.23, p=.013$, parent-report: $\chi^{2}(1)=.451, p=.502$ ).

Using two of the symptom impact items ('How much do these difficulties upset or distress you/your child?' and 'How much do these difficulties get in the way of your/your child's everyday life at school?') in combination with the 11 RCADS items achieved AUC values of .82-.90, with optimal cut-off total scores associated with sensitivity/specificity values of $.84 / .72$ and $.82 / .80$ for adolescent-report and parent-report respectively. The results of binary logistic regressions showed that adding these two impact items improved the overall identification of adolescents in the clinic-referred sample, using both adolescent-report $\left(\chi^{2}(1)=26.59, p<.01\right)$ and parent-report $\left(\chi^{2}(1)=17.06, p<.01\right)$. Notably, the two impact questions better predicted whether adolescents were in the clinic-referred sample or the community sample than the symptom items (odds ratio [OR] 1.12 and 1.16, compared to 1.85 and 1.69, for adolescent- and parent-report respectively). 


\section{Combining respondents}

Both adolescent- and parent-report made a significant contribution to identifying adolescents in the clinic-referred anxiety subsample versus the community sample $(\mathrm{OR}=1.15$ and 1.35 , respectively). Adding parent-report improved the overall logistic regression model $\left(\chi^{2}(1)=\right.$ 69.08, $p<.01$ ), indicating that a combination of adolescent-report and parent-report provides more accurate identification of adolescents with anxiety disorders than adolescent-report alone. Adolescent-report and parent-report depression items both significantly contributed to accurate identification of depressive disorders $(\mathrm{OR}=1.49$ and 1.33, respectively, $p<.01)$. Adding parent-report improved the overall regression model fit $\left(\chi^{2}(1)=26.00, p<.01\right)$, indicating that the combination of adolescent- and parent-report leads to the most accurate identification of adolescents with depressive disorders.

\section{Psychometric evaluation of the 11 RCADS items and comparison with the original RCADS-47 and the RCADS-25}

Internal Consistency: The McDonald's omega coefficient for the 11 RCADS items ranged from .72-.88 in the total clinic-referred sample, $.73-.88$ in the clinic-referred anxiety subsample, $.70-.78$ in the clinic-referred depression subsample and $.87-.94$ in the community sample, demonstrating acceptable/good internal consistency. McDonald's omega coefficients with 95\% confidence intervals for the 11-item RCADS total score and the 5 item depression score/ 6 item anxiety score, and the original RCADS and RCADS-25 are outlined in Appendix D.

Convergent and divergent validity: The correlation coefficients between the 5 item depression score and the MFQ-C/P total scores were moderate to high (ranging from .63 to .80, $p<.01)$ in the community sample, total clinic-referred sample and both clinic-referred subsamples, demonstrating favourable convergent validity. Similarly, correlations between 6item anxiety score and MFQ-C/P total scores were at least moderate $(.50$ to $.77, p<.01)$ in the 
community sample, total clinic-referred sample, and clinic-referred anxiety subsample, but weak to moderate $(\leq .44, p>0.01)$ in the clinic-referred depression subsample. Corresponding convergent/divergent validity coefficients for the original RCADS and the RCADS-25 were comparable to those for the 11-item RCADS, with similar patterns of associations in each sample (see Appendix E).

Criterion validity/ROC curve analyses: The AUC and optimal cut-off scores, with corresponding sensitivity/specificity values for the 11-item RCADS, the original RCADS, and the RCADS-25 are outlined in Table 6 (adolescent-report) and Appendix F (parent-report). Analyses are presented for the total sample and subsamples (girls, boys, older and younger adolescents $)^{2}$.

Table 3. ROC curve analyses for the 11-items from RCADS-C (current study), the original RCADS-C, and the RCADS-25-C

\begin{tabular}{|c|c|c|c|c|c|c|c|c|c|}
\hline \multirow[b]{2}{*}{ Number of items } & \multicolumn{3}{|c|}{ RCADS: Anxiety } & \multicolumn{3}{|c|}{ RCADS: Depression } & \multicolumn{3}{|c|}{ RCADS: Total } \\
\hline & $6^{\mathrm{a}}$ & $37^{\mathrm{b}}$ & $15^{\mathrm{c}}$ & $5^{\mathrm{a}}$ & $10^{\mathrm{b}}$ & $10^{\mathrm{c}}$ & $11^{\mathrm{a}}$ & $47^{\mathrm{b}}$ & $25^{\mathrm{c}}$ \\
\hline \multicolumn{10}{|l|}{ Total } \\
\hline AUC & .81 & .74 & .71 & .87 & .86 & .86 & .82 & .76 & .75 \\
\hline Cut-off & 7.5 & 44.5 & 13.5 & 8.5 & 15.5 & 15.5 & 12.5 & 56.1 & 27 \\
\hline $\begin{array}{l}\text { Sensitivity/ } \\
\text { Specificity } \\
n \text { (positive; }\end{array}$ & $.77 / .74$ & $.70 / .69$ & $.73 / .61$ & $.82 / .77$ & $.76 / .76$ & $.76 / .76$ & $.80 / .71$ & $.71 / .70$ & $.70 / .68$ \\
\hline negative) & $221 ; 226$ & $228 ; 230$ & $229 ; 229$ & $79 ; 366$ & $80 ; 379$ & $80 ; 379$ & $230 ; 204$ & $244 ; 214$ & $245 ; 214$ \\
\hline \multicolumn{10}{|l|}{ Boys } \\
\hline AUC & .85 & .78 & .72 & .93 & .93 & .93 & .87 & .81 & .78 \\
\hline Cut-off & 4.5 & 32.4 & 10.9 & 7.5 & 13.5 & 13.5 & 8.5 & 42.9 & 21.5 \\
\hline $\begin{array}{l}\text { Sensitivity/ } \\
\text { Specificity } \\
n \text { (positive: }\end{array}$ & $.83 / .75$ & $.74 / .71$ & $.70 / .62$ & $.88 / .83$ & $.88 / .77$ & $.88 / .77$ & $.84 / .70$ & $.75 / .75$ & $.75 / .74$ \\
\hline negative) & $48 ; 95$ & $53 ; 95$ & $53 ; 95$ & $17 ; 126$ & $17 ; 131$ & $17 ; 131$ & $51 ; 87$ & $57 ; 91$ & $57 ; 91$ \\
\hline \multicolumn{10}{|l|}{ Girls } \\
\hline AUC & .77 & .71 & .68 & .84 & .83 & .83 & .77 & .72 & .71 \\
\hline Cut-off & 8.5 & 45.1 & 15.5 & 8.5 & 15.5 & 15.5 & 14.5 & 59.5 & 28.6 \\
\hline $\begin{array}{l}\text { Sensitivity/ } \\
\text { Specificity } \\
n \text { (positive; }\end{array}$ & $.73 / .70$ & $.74 / .62$ & $.68 / .61$ & $.82 / .71$ & $.75 / .71$ & $.75 / .71$ & $.72 / .68$ & $.70 / .64$ & $.70 / .62$ \\
\hline $\begin{array}{l}\text { negative) } \\
\text { Older } \\
\text { adolescents }\end{array}$ & $173 ; 131$ & $175 ; 135$ & $176 ; 134$ & $62 ; 240$ & $63 ; 248$ & $63 ; 248$ & $179 ; 117$ & $187 ; 123$ & $188 ; 123$ \\
\hline
\end{tabular}

\footnotetext{
${ }^{2}$ Sample sizes for adolescent boys and younger adolescents in the clinic-referred depression subsample were less than 30 ( $n=17$ and 21). The post-hoc power calculations determined that the results based on these sample sizes at the given AUC were still sufficiently powered.
} 


\begin{tabular}{rccccccccc} 
AUC & .82 & .75 & .73 & .83 & .82 & .82 & .84 & .77 & .77 \\
$\begin{array}{r}\text { Cut-off } \\
\text { Sensitivity/ }\end{array}$ & 7.5 & 45.1 & 14.5 & 8.5 & 15.5 & 15.5 & 14.5 & 58.1 & 28.6 \\
$\begin{array}{r}\text { Specificity } \\
n \text { (positive; }\end{array}$ & $.81 / .80$ & $.71 / .70$ & $.70 / .65$ & $.79 / .70$ & $.73 / .72$ & $.73 / .72$ & $.80 / .76$ & $.73 / .73$ & $.73 / .73$ \\
$\begin{array}{r}\text { negative) } \\
\text { Younger }\end{array}$ & $110 ; 77$ & $112 ; 80$ & $113 ; 79$ & $58 ; 131$ & $59 ; 134$ & $59 ; 134$ & $120 ; 63$ & $126 ; 66$ & $127 ; 66$ \\
adolescents & & & & & & & & & \\
AUC & .80 & .74 & .70 & .92 & .92 & .92 & .78 & .75 & .73 \\
$\begin{array}{r}\text { Cut-off } \\
\text { Sensitivity/ }\end{array}$ & 7.5 & 41.6 & 13.5 & 8.5 & 16.8 & 16.8 & 11.5 & 51.5 & 23.5 \\
$\begin{array}{r}\text { Specificity } \\
n \text { (positive; } \\
\text { negative) }\end{array}$ & $.74 / .72$ & $.72 / .67$ & $.72 / .61$ & $.90 / .80$ & $.86 / .83$ & $.86 / .83$ & $.78 / .66$ & $.70 / .65$ & $.68 / .61$ \\
\hline
\end{tabular}

Note. ${ }^{\mathrm{a}} 11$-item RCADS-C, ${ }^{\mathrm{b}} \mathrm{RCADS}-\mathrm{C},{ }^{\mathrm{c}} \mathrm{RCADS}-25-\mathrm{C}$.

The brief adolescent-report for anxiety ( 6 items)/depression (5 items)/total (11 items) identified adolescents with either an anxiety or depressive disorder with a moderate-to-good level of accuracy, with AUC values $>.70$ (.77-.93). The optimal cut-off score for the anxiety items, depression items and total were associated with sensitivity/specificity values $>.80 / .70$ or $>$ $.70 / .70$ in each group, with the exception of the 11-item RCADS total score among adolescent girls (sensitivity/specificity .72/.68) and younger adolescents (sensitivity/specificity .78/.66). The original RCADS and RCADS-25 achieved AUC values >.60 (.68-.93), although the optimal cut-off scores were associated with more varied sensitivity/specificity values than corresponding values for the 11-item RCADS total score, ranging from .68/.61 and .74/.71 for the RCADS and RCADS-25 anxiety subscales respectively to $.73 / .72$ and $.86 / .83$ for the RCADS and RCADS-25 depression subscales.

The parent-report 11-item RCADS total score discriminated between adolescents in the community sample and adolescents in the clinic-referred sample with a good level of accuracy, with AUC values $>.80$ (.83 to .91$)$. The sensitivity/specificity values $>.80 / .70$ or $>.70 / .70$ were achieved for the parent-report 5 anxiety items, 6 depression items and the 11-item total score in each group, ranging from $.75 / .75$ to $.84 / .83$ for the 6 anxiety items, and from $.82 / .74$ to $.93 / .75$ for the 5 depression items. The original RCADS-P and RCADS-25-P similarly achieved AUC values $>.80$, although notably, the sensitivity/specificity values associated with the 
optimal cut-off scores on the RCADS-P and RCADS-P-25 did not exceed corresponding values for the 11-item RCADS-P, and this trend was consistent across both age and gender groups. 


\section{Discussion}

Brief and accurate screening measures for symptoms of anxiety and depression in adolescents are needed to help identify young people with these commonly occurring mental health problems in community settings, such as schools or primary care services. Consequently, we identified 11 items from the widely-used RCADS to screen for DSM-5 anxiety and depressive disorders symptoms within this specific age range that were able to discriminate between the community sample of adolescents and a clinic-referred sample of adolescents with an anxiety/depressive disorder diagnosis. The study also identified two optional symptom impact questions that further increased the accuracy of 11 RCADS symptom items (items and scoring details are available in Appendix G and on the RCADS authors' website).

Two additional symptom impact items related to distress and interference at school further improved the accuracy of 11 RCADS adolescent- and parent-report symptom items, and notably, were able to better discriminate between adolescents in the community and clinicreferred sample than the symptom items alone. The superiority of impact items over symptom items when predicting mental health problems in children and adolescents is consistent with previous research (Evans et al., 2017; Goodman, 1999; Stringaris \& Goodman, 2013). Items assessing adolescent's suicidal ideation on the other hand did not improve the accuracy of a brief set of depression items. Although suicidal ideation represents a common characteristic of adolescent depression in clinic-referred samples (e.g. Orchard et al., 2017), large-scale community studies (e.g. Vander Stoep, Mccauley, Flynn, \& Stone, 2009) suggest that suicidal ideation is common in non-help-seeking populations as well with over $60 \%$ of adolescents experiencing suicidal thoughts at least once over the course of 18 months. Suicidal ideation, therefore, might not be a key characteristic that distinguishes adolescents in clinic-referred samples from those in community samples. 
We found that using both adolescent-report and parent-report of the 11 RCADS items led to the most accurate discrimination between the community and clinic-referred sample of adolescents with anxiety/depressive disorder diagnosis, which is consistent with previous research (e.g. Choudhury, Pimentel, \& Kendall, 1998; Goodman, Ford, Simmons, Gatward, \& Meltzer, 2000; Villabø, Gere, Torgersen, March, \& Kendall, 2012). In discriminating between a clinic-referred depression subsample and community sample, adolescent-report was superior to parent-report. However, perhaps surprisingly within this age group, in discriminating between a clinic-referred anxiety subsample and community sample, parent-report was better than adolescent-report. These findings are consistent with previous studies comparing single informants for identifying anxiety disorders (Reardon et al., 2017) and depression (Lewis et al., 2014) in children and young people. It might be that the parents are more able to detect symptoms of observable behaviours, including anxiety, but not depressive symptoms, which are usually less noticeable (Martel et al., 2017).

Together the 11 RCADS items demonstrated good psychometric properties which were comparable with those of the original RCADS and RCADS-25. Overall, sensitivity/specificity values of the depression and anxiety scores and the total score were at least $>.70 / .70$, which was replicated across different age and gender groups, with the exception of the total score for adolescent girls and younger adolescents (sensitivity/specificity values of .72/.68 and .78/.66, respectively).

The internal consistency of the adolescent- and parent-report 11-item total score and 5item depression score were good (McDonald's omega coefficients $>.80$ ) in the community sample, total clinic-referred sample, and clinic-referred anxiety subsample, although the adolescent- and parent-reported 6-item anxiety score demonstrated slightly lower, yet still acceptable, internal consistency values in the clinic-referred samples. Notably, the 11-item RCADS, as well as the original RCADS and RCADS-25 demonstrated better internal 
consistency in the community sample compared to the clinic-referred sample, consistent with previous research using the original RCADS and RCADS-25 (Piqueras et al., 2017).

The 5 RCADS depression items for adolescent- and parent-report strongly correlated with the MFQ-C/P evidencing convergent validity. Correlation coefficients between the 6 RCADS anxiety items and MFQ-C/P (divergent validity) were lower albeit still moderate and in most cases significant. This lack of divergent validity probably reflects high levels of comorbidity between anxiety and depressive symptoms in adolescents (Cummings et al., 2014; Essau, 2003; Seligman \& Ollendick, 1998). Notably, the 11 RCADS items, and the original RCADS/RCADS-25 demonstrated similar patterns of convergent and divergent validity for anxiety/depression scores for adolescent- and parent-report.

\section{Implications}

Due to the brevity, easy administration/scoring, and good levels of sensitivity and specificity, the 11 RCADS items identified in this study have potential for use in community settings, such as schools and primary care, as a measure to screen for anxiety or depressive disorders. For adolescent-report, we recommend using cut-off scores of $\geq 5$ for adolescent boys, and $\geq 9$ for adolescent girls (anxiety score), $\geq 8$ for adolescent boys, and $\geq 9$ for adolescent girls (depression score), and $\geq 9$ for adolescent boys and $\geq 14$ for adolescent girls (total score). Using additional impact questions, the cut-off for the total score increases to $\geq 14$ for adolescent boys and $\geq 18$ for adolescent girls. When using parent-report, we recommend using cut-offs of $\geq 5$ (adolescent boys) and $\geq 7$ (adolescent girls) for the anxiety score, $\geq 6$ (adolescent boys) and $\geq 7$ (adolescent girls) for the depression score, $\geq 8$ (adolescent boys) and $\geq 11$ (adolescent girls) for total score and $\geq 13$ (adolescent boys) and $\geq 15$ (adolescent girls) for total score with additional impact items.

To increase the accuracy of 11 RCADS items we recommend using additional symptom impact items. Adolescents'/parents' responses to these two items should be interpreted in 
relation to the total score and not in relation to the depression or anxiety symptom scores alone. Our findings suggest that each respondent (i.e. adolescent and parent) makes a significant contribution to the identifying adolescents with anxiety and/or depressive disorders, which warrants the single-informant approach in situations when only adolescent/parent is available. Ideally, the 11-RCADS items plus symptom impact items should be completed by both the adolescent and their parent/carer as this leads to the most accurate identification of young people with anxiety/depression. The items have the potential to be used on an individual basis, such as in primary care, or as a part of universal screening for anxiety and depressive disorders in schools. In each case, the items should be administered by well-trained health/social care/education professionals, who are familiar with standard procedures (e.g. referral of adolescents to the appropriate services). Although the items assessing adolescent's suicidal ideation are not included in the final brief set of items, it is important that the thorough risk assessment is carried out with adolescents scoring above the threshold for the depression items (National Institute for Health and Care Excellence, 2019).

\section{Strengths and limitations}

We applied a rigorous methodological process to identify a brief set of RCADS items that are easy to use/interpret, and psychometrically adequate to discriminate between adolescents in a community sample and adolescents with a diagnosis of anxiety and/or depressive disorder diagnosis. The 11-item set from the RCADS was able to discriminate between those two groups of adolescents with comparable accuracy to the original RCADS and RCADS-25. The 11 items take only a few minutes to be completed, producing clear cut-off scores and the same items are used in both the adolescent- and parent-report versions, meaning items completed by different respondents can be easily compared. As such, the brief set of 11 items has the potential for use in community settings where the primary purpse is to screen for any anxiety or depressive disorder, and administering longer questionnaires may not be feasible.. 
Nevertheless, our study has several limitations. First, only participants in the clinicreferred sample, and not those in the community sample, were assessed using the standardised diagnostic interviews. Given the prevalence rates of anxiety and depressive disorders in adolescents, some participants in the community sample might have met the criteria for anxiety and/or depressive disorders and were wrongly classified as participants without an anxiety/depressive disorder diagnosis (false negatives). In addition, the two samples were recruited through different methods (i.e. community sample through local secondary schools and clinic-referred sample through university-based clinic), and all participants in the clinicreferred sample were a help-seeking population (i.e. higher percentage of females and higher mean age than in a community sample) which might have contributed to differences between the samples. As the clinic-referred sample was recruited through a specialiased (anxiety and depression) clinic, our findings have limited generalisability to other diagnostically heterogenous clinic-referred samples. Furthermore, we used the same samples to both develop and evaluate items. Unlike the original RCADS, the brief set of 11 items do not provide information about specific anxiety disorders. In addition, the original RCADS and RCADS-25 items were developed through different methodological procedures and for different purposes than this briref screening tool, making it hard to draw direct comparisons between the psychometric characteristics of all three questionnaire measures. Finally, although we used an opt-out approach to collect adolescent-report questionnaires, which is recommended to maximise student participation and increase demographic variability (Eaton et al., 2004; Liu et al., 2017), parent response rates were still low (18.7\%), and we are unable to establish the extent to which the community sample might differ from the wider population.

\section{Future research}

Our findings highlighted several possibilities for future research. First, the screening items should be re-evaluated in a new community sample of adolescents and their parents. Paricipants 
in the community sample should be assessed with standardised diagnostic assessments so that the capacity to identify adolsecents with and without specific anxiety/depressive disorders in the community can be evaluated. Finally, similar to the use of brief anxiety and mood measures to monitor routine clinical outcomes in adult services (Gyani et al., 2013), this brief set of items have the potential to be applied beyond screening purposes, such as to monitor progress through treatment of anxiety and depressive disorders in adoelscents and, as such, the items' sensitivity to change warrants specific examination. 


\section{References}

Aebi, M., Kuhn, C., Banaschewski, T., Grimmer, Y., Poustka, L., Steinhausen, H. C., \& Goodman, R. (2017). The contribution of parent and youth information to identify mental health disorders or problems in adolescents. Child and Adolescent Psychiatry and Mental Health, 11(1), 1-12. https://doi.org/10.1186/s13034-017-0160-9

Albano, A. M., \& Silverman, W. K. (1996). The Anxiety Disorders Interview Schedule for Children for DSM-IV: Clinician manual (child and parent versions). San Antonio, TX: Psychological Corporation.

American Psychiatric Association. (2000). Diagnostic and Statistical Manual for Mental Disorders-IV-TR. Arlington, VA: American Psychiatric Publishing.

American Psychiatric Association. (2013). Diagnostic and statistical manual of mental disorders (DSM-5) (American Psychiatric Association (ed.)). American Psychiatric Pub.

Angold, A., \& Costello, E. (1987). Mood and Feelings Questionnaire (MFQ). Developmental Epidemiology Program, Duke University.

Axelson, D. A., \& Birmaher, B. (2001). Relation between anxiety and depressive disorders in childhood and adolescence. Depression and Anxiety, 14(2), 67-78. https://doi.org/10.1002/da.1048

Becker, A., Woerner, W., Hasselhorn, M., Banaschewski, T., \& Rothenberger, A. (2004). Validation of the parent and teacher SDQ in a clinical sample. European Child \& Adolescent Psychiatry, 13 Suppl 2, II11-6. https://doi.org/10.1007/s00787-004-2003-5

Chorpita, B. F., Moffitt, C. E., \& Gray, J. (2005). Psychometric properties of the Revised Child Anxiety and Depression Scale in a clinical sample. Behaviour Research and Therapy, 43(3), 309-322. https://doi.org/10.1016/j.brat.2004.02.004

Chorpita, B. F., Yim, L., Moffitt, C., Umemoto, L. A., \& Francis, S. E. (2000). Assessment of symptoms of DSM-IV anxiety and depression in children: A revised child anxiety and depression scale. Behaviour Research and Therapy, 38(8), 835-855. https://doi.org/10.1016/S0005-7967(99)00130-8

Choudhury, M. S., Pimentel, S. S., \& Kendall, P. C. (1998). Childhood Anxiety Disorders : Parent - Child ( Dis ) Agreement Using a Structured Interview for the DSM-IV. 42(8), 957-964. https://doi.org/10.1097/01.CHI.0000046898.27264.A2

Cummings, C. M., Caporino, N. E., \& Kendall, P. C. (2014). Comorbidity of anxiety and depression in children and adolescents: 20 years after. Psychological Bulletin, 140(3), 816-845. https://doi.org/10.1037/a0034733

Deighton, J., Croudace, T., Fonagy, P., Brown, J., Patalay, P., \& Wolpert, M. (2014). Measuring mental health and wellbeing outcomes for children and adolescents to inform practice and policy: a review of child self-report measures. Child and Adolescent Psychiatry and Mental Health, 8(1), 14. https://doi.org/10.1186/1753-2000-8-14

Department of Health, \& Department of Education. (2017). Transforming Children and Young People's Mental Health Provision: a Green Paper (Issue December). https://assets.publishing.service.gov.uk/government/uploads/system/uploads/attachment_ data/file/664855/Transforming_children_and_young_people_s_mental_health_provision .pdf

Donnelly, A., Fitzgerald, A., Shevlin, M., Dooley, B., Donnelly, A., Fitzgerald, A., Shevlin, M., Dooley, B., \& Shevlin, M. (2019). Investigating the psychometric properties of the 
revised child anxiety and depression scale ( RCADS ) in a non-clinical sample of Irish adolescents Investigating the psychometric properties of the revised child anxiety and depression scale ( RCADS ) in a . Journal of Mental Health, 00(00), 1-12. https://doi.org/10.1080/09638237.2018.1437604

Dowdy, E., Furlong, M., Eklund, K., Saeki, E., \& Ritchey, K. (2010). Screening for Mental Health and Wellness: Current School-Based Practices and Emerging Possibilities. In B. Doll, W. Pfohl, \& J. Yoon (Eds.), Handbook of Youth Prevention Science (p. 26). Routledge. https://doi.org/https://doi.org/10.4324/9780203866412

Eaton, D. K., Lowry, R., Brener, N. D., Grunbaum, J. A., \& Kann, L. (2004). Passive versus active parental permission in school-based survey research: Does the type of permission affect prevalence estimates of risk behaviors? Evaluation Review, 28(6), 564-577. https://doi.org/10.1177/0193841X04265651

Ebesutani, C., Bernstein, A., Nakamura, B. J., Chorpita, B. F., \& Weisz, J. R. (2010). A psychometric analysis of the revised child anxiety and depression scale-parent version in a clinical sample. Journal of Abnormal Child Psychology, 38(2), 249-260. https://doi.org/10.1007/s10802-009-9363-8

Ebesutani, C., Korathu-Larson, P., Nakamura, B. J., Higa-McMillan, C., \& Chorpita, B. (2017). The Revised Child Anxiety and Depression Scale 25-Parent Version: Scale Development and Validation in a School-Based and Clinical Sample. Assessment, 24(6), 712-728. https://doi.org/10.1177/1073191115627012

Ebesutani, C., Reise, S. P., Chorpita, B. F., Ale, C., Regan, J., Young, J., Charmaine, H. M. M., \& Weisz, J. R. (2012). The Revised Child Anxiety and Depression Scale-Short Version: Scale reduction via exploratory bifactor modeling of the broad anxiety factor. Psychological Assessment, 24(4), 833-845. https://doi.org/10.1037/a0027283

Essau, C. A. (2003). COMORBIDITY OF ANXIETY DISORDERS IN . 6(September 2000), 16. https://doi.org/10.1002/da.10107

Essau, C. A. (2008). Comorbidity of depressive disorders among adolescents in community and clinical settings. Psychiatry Research, 158(1), 35-42. https://doi.org/10.1016/j.psychres.2007.09.007

Evans, R., Thirlwall, K., Cooper, P., \& Creswell, C. (2017). Using symptom and interference questionnaires to identify recovery among children with anxiety disorders. In Psychological Assessment (Vol. 29, Issue 7, pp. 835-843). https://doi.org/10.1037/pas0000375

Glover, T. A., \& Albers, C. A. (2007). Considerations for evaluating universal screening assessments. Journal of School Psychology, 45(2), 117-135. https://doi.org/10.1016/j.jsp.2006.05.005

Goodman, R. (1999). The extended version of the Strengths and Difficulties Questionnaire as a guide to child psychiatric caseness and consequent burden. Journal of Child Psychology and Psychiatry, and Allied Disciplines, 40(5), 791-799. http://www.ncbi.nlm.nih.gov/pubmed/10433412

Goodman, R. (2001). Psychometric properties of the strengths and difficulties questionnaire. Journal of the American Academy of Child and Adolescent Psychiatry, 40(11), 13371345. https://doi.org/10.1097/00004583-200111000-00015

Gyani, A., Shafran, R., Layard, R., \& Clark, D. M. (2013). Enhancing recovery rates: lessons from year one of IAPT. Behaviour Research and Therapy, 51(9), 597-606.

https://doi.org/10.1016/j.brat.2013.06.004 
Hammerton, G., Zammit, S., Potter, R., Thapar, A., \& Collishaw, S. (2014). Validation of a composite of suicide items from the Mood and Feelings Questionnaire (MFQ) in offspring of recurrently depressed parents. Psychiatry Research, 216(1), 82-88. https://doi.org/10.1016/j.psychres.2014.01.040

Johnson, S. E., Lawrence, D., Hafekost, J., Saw, S., Buckingham, W. J., Sawyer, M., Ainley, J., \& Zubrick, S. R. (2016). Service use by Australian children for emotional and behavioural problems: Findings from the second Australian Child and Adolescent Survey of Mental Health and Wellbeing. Australian \& New Zealand Journal of Psychiatry, 50(9), 887-898. https://doi.org/10.1177/0004867415622562

Jonge, T. De, Veenhoven, R., \& Arends, L. (2014). Homogenizing Responses to Different Survey Questions on the Same Topic: Proposal of a Scale Homogenization Method Using a Reference Distribution. 275-300. https://doi.org/10.1007/s11205-013-0335-6

Kaufman, Joan, Birmaher, B., Axelson, D., Perepletchikova, F., Brent, D., \& Ryan, N. (2016). K-SADS-PL. Child and Adolescent Research and Education Program, Yale University.

Kaufman, JOAN, BIRMAHER, B., BRENT, D., Rao, U. M. A., Flynn, C., MORECI, P., Williamson, D., \& Ryan, N. (1997). Schedule for Affective Disorders and Schizophrenia for School-Age Children-Present and Lifetime Version (K-SADS-PL): Initial Reliability and Validity Data. Journal of the American Academy of Child and Adolescent Psychiatry, 36(7), 980-988. https://doi.org/10.1097/00004583-199707000-00021

Kraemer, H. C. (1992). Evaluating medical tests: Objective and quantitative guidelines. Sage Publications Ltd.

Kroenke, K., Spitzer, R. L., \& Williams, J. B. W. (2001). The PHQ-9. Journal of General Internal Medicine, 16(9), 606-613.

Kuhn, C., Aebi, M., Jakobsen, H., Banaschewski, T., Poustka, L., Grimmer, Y., Goodman, R., \& Steinhausen, H.-C. (2017). Effective Mental Health Screening in Adolescents: Should We Collect Data from Youth, Parents or Both? Child Psychiatry and Human Development, 48(3), 385-392. https://doi.org/10.1007/s10578-016-0665-0

Lawrence, D., Johnson, S., Hafekost, J., Boterhoven de Haan, K., Sawyer, M., Ainley, J., \& Zubrick, S. R. (2015). The Mental Health of Children and Adolescents. Report on the second Australian Child and Adolescent Survey of Mental Health and Wellbeing (Issue March). Department of Health.

LeDell, E., Petersen, M., \& Van der Laan, M. (2014). cvAUC: Cross-Validated Area Under the ROC Curve Confidence Intervals (R package version 1.1.0).

Lewis, A. J., Bertino, M. D., Bailey, C. M., Skewes, J., Lubman, D. I., \& Toumbourou, J. W. (2014). Depression and suicidal behavior in adolescents : a multi-informant and multimethods approach to diagnostic classification. Frontiers in Psychology, 5(July), 1-9. https://doi.org/10.3389/fpsyg.2014.00766

Liu, C., Cox, R. B., Washburn, I. J., Croff, J. M., \& Crethar, H. C. (2017). The Effects of Requiring Parental Consent for Research on Adolescents' Risk Behaviors: A Metaanalysis. Journal of Adolescent Health, 61(1), 45-52. https://doi.org/10.1016/j.jadohealth.2017.01.015

Lyneham, H. J., Abbott, M. J., \& Rapee, R. M. (2007). Interrater reliability of the anxiety disorders interview schedule for DSM-IV: Child and parent version. Journal of the American Academy of Child and Adolescent Psychiatry, 46(6), 731-736. https://doi.org/10.1097/chi.0b013e3180465a09 
Martel, M. M., Markon, K., \& Smith, G. T. (2017). Research Review: Multi-informant integration in child and adolescent psychopathology diagnosis. Journal of Child Psychology and Psychiatry, and Allied Disciplines, 58(2), 116-128. https://doi.org/10.1111/jcpp.12611

Merikangas, K. R., He, J. P., Brody, D., Fisher, P. W., Bourdon, K., \& Koretz, D. S. (2010). Prevalence and Treatment of Mental Disorders Among US Children in the 2001-2004 NHANES. Pediatrics, 125(1), 75-81. https://doi.org/10.1542/peds.2008-2598

Myers, K., \& Winters, N. C. (2002). Ten-Year Review of Rating Scales. I: Overview of Scale Functioning, Psychometric Properties, and Selection. Journal of the American Academy of Child and Adolescent Psychiatry, 41(2), 114-122. https://doi.org/10.1097/00004583200202000-00004

National Institute for Health and Care Excellence. (2019). Depression in children and y young oung people : identification and management. June. www.nice.org.uk/guidance/ng134

Orchard, F., Pass, L., Marshall, T., \& Reynolds, S. (2017). Clinical characteristics of adolescents referred for treatment of depressive disorders. Child and Adolescent Mental Health, 22(2), 61-68. https://doi.org/10.1111/camh.12178

Peters, G. (2018)._userfriendlyscience: Quantitative analysis made accessible_. https://doi.org/10.17605/osf.io/txequ

Piqueras, J. A., Martín-vivar, M., Sandin, B., San, C., \& Pineda, D. (2017). Journal of A ff ective Disorders The Revised Child Anxiety and Depression Scale : A systematic review and reliability generalization meta-analysis. Journal of Affective Disorders, 218(December 2016), 153-169. https://doi.org/10.1016/j.jad.2017.04.022

Polanczyk, G. V., Salum, G. A., Sugaya, L. S., Caye, A., \& Rohde, L. A. (2015). Annual research review: A meta-analysis of the worldwide prevalence of mental disorders in children and adolescents. Journal of Child Psychology and Psychiatry and Allied Disciplines, 56(3), 345-365. https://doi.org/10.1111/jcpp.12381

R Core Team. (2019). $R$ : A language and environment for statistical computing (3.6.1). R Foundation for Statistical Computing. https://www.r-project.org/

Reardon, T., Spence, S. H., Hesse, J., Shakir, A., \& Creswell, C. (2017). Identifying children with anxiety disorders using brief versions of the Spence Children's Anxiety Scale for children, parents and teachers. Psychological Assessment: A Journal of Consulting and Clinical Psychology, In press.

Revelle, W. (2018). psych: Procedures for Personality and Psychological Research (R package version 1.8.12). Northwestern University. https://cran.rproject.org/package $=$ psych

Riegler, A., Völkl-Kernstock, S., Lesch, O., Walter, H., \& Skala, K. (2017). Attention deficit hyperactivity disorder and substance abuse: An investigation in young Austrian males. Journal of Affective Disorders, 217, 60-65. https://doi.org/10.1016/j.jad.2017.03.072

Robin, X., Turck, N., Hainard, A., Tiberti, N., Lisacek, F., Sanchez, J.-C., \& Müller, M. (2011).pROC: an open-source package for R and $\mathrm{S}+$ to analyze and compare ROC curves. BMC Bioinformatics, 12(1), 77. https://doi.org/10.1186/1471-2105-12-77

Sadler, K., Vizard, Ti., Ford, T., Goodman, A., Goodman, R., \& McManus, S. (2018). Mental Health of Children and Young People in England, 2017. Health and Social Care Information Centre.

Seligman, L. D., \& Ollendick, T. H. (1998). Comorbidity of Anxiety and Depression in 
Children and Adolescents: An Integrative Review. Clinical Child and Family Psychology Review, 1(2), 125-144. https://doi.org/10.1023/A:1021887712873

Silverman, W. K., Saavedra, L. M., \& Pina, A. A. (2001). Test-retest reliability of anxiety symptoms and diagnoses with the anxiety disorders interview schedule for DSM-IV: Child and parent versions. Journal of the American Academy of Child and Adolescent Psychiatry, 40(8), 937-944. https://doi.org/10.1097/00004583-200108000-00016

Siu, A. L., \& U S Preventive Services Task Force. (2016). Screening for depression in adults: Us preventive services task force recommendation statement. JAMA, 315(4), 380-387. http://dx.doi.org/10.1001/jama.2015.18392

Spence, S. H. (1997). Structure of anxiety symptoms among children: a confirmatory factoranalytic study. Journal of Abnormal Psychology, 106(2), 280.

Spence, S. H. (1998). A measure of anxiety symptoms among children. Behaviour Research and Therapy, 36(5), 545-566.

Spence, S. H. (2018). Assessing anxiety disorders in children and adolescents. 3, 266-282. https://doi.org/10.1111/camh.12251

Spitzer, R. L., Kroenke, K., Williams, J. B. W., \& Lowe, B. (2006). A brief measure for assessing generalized anxiety disorder: the GAD-7. Archives of Internal Medicine, 166(10), 1092-1097. https://doi.org/10.1001/archinte.166.10.1092

Stringaris, A., \& Goodman, R. (2013). The value of measuring impact alongside symptoms in children and adolescents: a longitudinal assessment in a community sample. Journal of Abnormal Child Psychology, 41(7), 1109-1120. https://doi.org/10.1007/s10802-0139744-x

Vander Stoep, A., Mccauley, E., Flynn, C., \& Stone, A. (2009). Thoughts of Death and Suicide in Early Adolescence. Suicide Life Threat Behav, 39(6), 1-18. https://doi.org/10.1521/suli.2009.39.6.599.

Villabø, M., Gere, M., Torgersen, S., March, J. S., \& Kendall, P. C. (2012). Diagnostic efficiency of the child and parent versions of the Multidimensional Anxiety Scale for Children. Journal of Clinical Child and Adolescent Psychology: The Official Journal for the Society of Clinical Child and Adolescent Psychology, American Psychological Association, Division 53, 41(1), 75-85. https://doi.org/10.1080/15374416.2012.632350

Whiteford, H. A., Degenhardt, L., Rehm, J., Baxter, A. J., Ferrari, A. J., Erskine, H. E., Charlson, F. J., Norman, R. E., Flaxman, A. D., Johns, N., Burstein, R., Murray, C. J. L., \& Vos, T. (2013). Global burden of disease attributable to mental and substance use disorders: Findings from the Global Burden of Disease Study 2010. The Lancet, 382(9904), 1575-1586. https://doi.org/10.1016/S0140-6736(13)61611-6

Wood, J. J., Piacentini, J. C., Bergman, R. L., McCracken, J., \& Barrios, V. (2002). Concurrent validity of the anxiety disorders section of the Anxiety Disorders Interview Schedule for DSM-IV: child and parent versions. Journal of Clinical Child and Adolescent Psychology: The Official Journal for the Society of Clinical Child and Adolescent Psychology, American Psychological Association, Division 53, 31(3), 335342. https://doi.org/10.1207/S15374424JCCP3103_05 


\section{Appendices}

\section{Appendix A}

Rank-ordered item-total correlations and item-discrimination indices for the RCADS-P items

\begin{tabular}{|c|c|c|c|c|c|}
\hline \multirow[b]{2}{*}{ Item number } & \multirow[b]{2}{*}{ Item (RCADS Subscale) } & \multicolumn{4}{|c|}{$\begin{array}{l}\text { Item-anxiety/depression } \\
\text { diagnosis correlation }\end{array}$} \\
\hline & & $\begin{array}{c}\text { Item- } \\
\text { total }\end{array}$ & Total & $\begin{array}{l}\text { Contro } \\
\text { lled for } \\
\text { Gender }\end{array}$ & $\begin{array}{l}\text { Contro } \\
\text { lled for } \\
\text { age }\end{array}$ \\
\hline & Anxiety Items & & & & \\
\hline RCADS-P35 & $\begin{array}{l}\text { My child worries about what is going to } \\
\text { happen (GAD) }\end{array}$ & $.81 *$ & $.44^{*}$ & $.42^{*}$ & $.45^{*}$ \\
\hline RCADS-P1 & My child worries about things (GAD) & $.79 *$ & $.43 *$ & $.40^{*}$ & $.43^{*}$ \\
\hline RCADS-P22 & $\begin{array}{l}\text { My child worries that bad things will } \\
\text { happen to him/her (GAD) }\end{array}$ & $.76^{*}$ & $.43^{*}$ & $.41^{*}$ & $.45^{*}$ \\
\hline RCADS-P30 & $\begin{array}{l}\text { My child worries about making mistakes } \\
\text { (SOC) }\end{array}$ & $.76^{*}$ & $.43 *$ & $.40^{*}$ & $.42 *$ \\
\hline RCADS-P27 & $\begin{array}{l}\text { My child worries that something bad will } \\
\text { happen to him/her (GAD) }\end{array}$ & $.76^{*}$ & $.40^{*}$ & $.38^{*}$ & $.42 *$ \\
\hline RCADS-P45 & $\begin{array}{l}\text { My child worries when in bed at night } \\
\text { (SEP) }\end{array}$ & $.74 *$ & $.49^{*}$ & $.47^{*}$ & $.50 *$ \\
\hline RCADS-P32 & $\begin{array}{l}\text { My child worries what other people think of } \\
\mathrm{him} / \mathrm{her} \text { (SOC) }\end{array}$ & $.74 *$ & $.48^{*}$ & $.45^{*}$ & $.48^{*}$ \\
\hline RCADS-P43 & $\begin{array}{l}\text { My child feels afraid that he/she will make } \\
\text { a fool of him/herself in front of people } \\
\text { (SOC) }\end{array}$ & $.74 *$ & $.49^{*}$ & $.46^{*}$ & $.48^{*}$ \\
\hline RCADS-P41 & $\begin{array}{l}\text { My child worries that he/she will suddenly } \\
\text { get a scared feeling when there is nothing to } \\
\text { be afraid of (PD) }\end{array}$ & $.73^{*}$ & $.42 *$ & $.40^{*}$ & $.42 *$ \\
\hline RCADS-P20 & $\begin{array}{l}\text { My child worries about looking foolish } \\
\text { (SOC) }\end{array}$ & $.73^{*}$ & $.53 *$ & $.50^{*}$ & $.53^{*}$ \\
\hline $\begin{array}{l}\text { RCADS- } \\
\text { P34 }\end{array}$ & $\begin{array}{l}\text { All of a sudden my child will feel really } \\
\text { scared for no reason at all (PD) }\end{array}$ & $.71^{*}$ & $.40^{*}$ & $.37 *$ & $.41 *$ \\
\hline RCADS-P4 & $\begin{array}{l}\text { My child worries when he/she thinks he/she } \\
\text { has done poorly at something (SOC) }\end{array}$ & $.70^{*}$ & $.35^{*}$ & $.32 *$ & $.34 *$ \\
\hline RCADS-P24 & $\begin{array}{l}\text { When my child has a problem, his/her heart } \\
\text { beats really fast (PD) }\end{array}$ & $.70^{*}$ & $.42 *$ & $.40^{*}$ & $.41 *$ \\
\hline RCADS-P7 & $\begin{array}{l}\text { My child feels scared when taking a test } \\
\text { (SOC) }\end{array}$ & $.70^{*}$ & $.36^{*}$ & $.33^{*}$ & $.36^{*}$ \\
\hline RCADS-P12 & $\begin{array}{l}\text { My child worries about doing badly at } \\
\text { school work (SOC) }\end{array}$ & $.69^{*}$ & $.41 *$ & $.38^{*}$ & $.40^{*}$ \\
\hline RCADS-P18 & $\begin{array}{l}\text { My child has trouble going to school in the } \\
\text { mornings because of feeling nervous or } \\
\text { afraid (SEP) }\end{array}$ & $.69^{*}$ & $.45^{*}$ & $.44^{*}$ & $.47^{*}$ \\
\hline RCADS-P28 & $\begin{array}{l}\text { When my child has a problem, he/she feels } \\
\text { shaky (PD) }\end{array}$ & $.67^{*}$ & $.39^{*}$ & $.37^{*}$ & $.39 *$ \\
\hline RCADS-P8 & $\begin{array}{l}\text { My child worries when he/she thinks } \\
\text { someone is angry with him/her (SOC) }\end{array}$ & $.67^{*}$ & $.33^{*}$ & $.31 *$ & $.34^{*}$ \\
\hline
\end{tabular}




\begin{tabular}{|c|c|c|c|c|c|}
\hline RCADS-P33 & $\begin{array}{l}\text { My child is afraid of being in crowded } \\
\text { places (like shopping centres, the cinema, } \\
\text { buses, busy playgrounds) (SEP) }\end{array}$ & $.66^{*}$ & $.41 *$ & $.39^{*}$ & $.42 *$ \\
\hline RCADS-P13 & $\begin{array}{l}\text { My child worries that something awful will } \\
\text { happen to someone in the family (GAD) }\end{array}$ & $.65^{*}$ & $.27^{*}$ & $.25^{*}$ & $.28^{*}$ \\
\hline RCADS-P3 & $\begin{array}{l}\text { When my child has a problem, he/she gets a } \\
\text { funny feeling in his/her stomach (PD) }\end{array}$ & $.63^{*}$ & $.41^{*}$ & $.38^{*}$ & $.41^{*}$ \\
\hline RCADS-P38 & $\begin{array}{l}\text { My child feels afraid if he/she has to talk in } \\
\text { front of the class (SOC) }\end{array}$ & $.63^{*}$ & $.38^{*}$ & $.36^{*}$ & $.38^{*}$ \\
\hline $\begin{array}{l}\text { RCADS- } \\
\text { P14 }\end{array}$ & $\begin{array}{l}\text { My child suddenly feels as if he/she can't } \\
\text { breathe when there is no reason for this } \\
\text { (PD) }\end{array}$ & $.61^{*}$ & $.31^{*}$ & $.28^{*}$ & $.30^{*}$ \\
\hline $\begin{array}{l}\text { RCADS- } \\
\text { P39a }\end{array}$ & $\begin{array}{l}\text { My child's heart suddenly starts to beat too } \\
\text { quickly for no reason (PD) }\end{array}$ & $.61 *$ & $.38^{*}$ & $.35^{*}$ & $.37^{*}$ \\
\hline RCADS-P46 & $\begin{array}{l}\text { My child would feel scared if he/she had to } \\
\text { stay away from home overnight (SEP) }\end{array}$ & $.56^{*}$ & $.31 *$ & $.29 *$ & $.33^{*}$ \\
\hline RCADS-P37 & My child thinks about death (GAD) & $.55^{*}$ & $.28^{*}$ & $.26^{*}$ & $.29 *$ \\
\hline $\begin{array}{l}\text { RCADS- } \\
\text { P26a }\end{array}$ & $\begin{array}{l}\text { My child suddenly start to tremble or shake } \\
\text { when there is no reason for this (PD) }\end{array}$ & $.54^{*}$ & $.29 *$ & $.27 *$ & $.28^{*}$ \\
\hline RCADS-P9 & $\begin{array}{l}\text { My child worries about being away from } \\
\text { me (SEP) }\end{array}$ & $.54^{*}$ & $.18^{*}$ & $.15^{*}$ & $.21^{*}$ \\
\hline RCADS-P5 & $\begin{array}{l}\text { My child feels afraid of being alone at } \\
\text { home (SEP) }\end{array}$ & $.51^{*}$ & $.23 *$ & $.20^{*}$ & $.24 *$ \\
\hline $\begin{array}{l}\text { RCADS- } \\
\text { P17 }\end{array}$ & $\begin{array}{l}\text { My child feels scared to sleep on his/her } \\
\text { own (SEP) }\end{array}$ & $.47^{*}$ & $.22 *$ & $.20^{*}$ & $.26^{*}$ \\
\hline \multirow[t]{2}{*}{$\begin{array}{l}\text { RCADS- } \\
\text { P36 }\end{array}$} & $\begin{array}{l}\text { My child suddenly become dizzy or faint } \\
\text { when there is no reason for this (PD) }\end{array}$ & $.43^{*}$ & $.22 *$ & $.19^{*}$ & $.21^{*}$ \\
\hline & Depression Items & & & & \\
\hline RCADS-P19 & My child has no energy for things (MDD) & $.83^{*}$ & $.42 *$ & $.41^{*}$ & $.39 *$ \\
\hline RCADS-P29 & My child feels worthless (MDD) & $.81 *$ & $.37 *$ & $.36^{*}$ & $.37^{*}$ \\
\hline RCADS-P21 & My child is tired a lot (MDD) & $.80^{*}$ & $.42 *$ & $.41 *$ & $.38^{*}$ \\
\hline RCADS-P2 & My child feels sad or empty (MDD) & $.78^{*}$ & $.40^{*}$ & $.39 *$ & $.39 *$ \\
\hline RCADS-P6 & $\begin{array}{l}\text { Nothing is much fun for my child anymore } \\
\text { (MDD) }\end{array}$ & $.76^{*}$ & $.39 *$ & $.38^{*}$ & $.37^{*}$ \\
\hline RCADS-P25 & My child cannot think clearly (MDD) & $.74 *$ & $.28^{*}$ & $.27^{*}$ & $.28^{*}$ \\
\hline RCADS-P11 & My child has trouble sleeping (MDD) & $.71 *$ & $.29 *$ & $.28^{*}$ & $.29 *$ \\
\hline RCADS-P40 & $\begin{array}{l}\text { My child feels like he/she doesn't want to } \\
\text { move (MDD) }\end{array}$ & $.69 *$ & $.30^{*}$ & $.28^{*}$ & $.28^{*}$ \\
\hline RCADS-P15 & $\begin{array}{l}\text { My child has problems with his/her appetite } \\
\text { (MDD) }\end{array}$ & $.68^{*}$ & $.29 *$ & $.27^{*}$ & $.27^{*}$ \\
\hline RCADS-P47 & My child feel restless (MDD) & $.67^{*}$ & $.25^{*}$ & $.24 *$ & $.23 *$ \\
\hline
\end{tabular}

Note. GAD $=$ generalised anxiety disorder, $\mathrm{PD}=$ panic disorder, $\mathrm{SOC}=$ social anxiety disorder, $\mathrm{SEP}=$ separation anxiety disorder, 'Item $>80 \%$ of responses 'never' in a community sample, ${ }^{*} p<.01$ 


\section{Appendix B}

ROC analyses for alternative combinations of adolescent-report anxiety items ( $\leq 12$ items) and depression items ( $\leq 9$ items) compared to original RCADS and RCADS-25.

\begin{tabular}{|c|c|c|c|c|c|c|c|c|c|c|c|c|}
\hline \multirow[b]{2}{*}{ Scale } & \multirow[b]{2}{*}{$\begin{array}{l}\text { Number } \\
\text { of items }\end{array}$} & \multicolumn{3}{|c|}{ Total } & \multicolumn{2}{|c|}{ Boys } & \multicolumn{2}{|c|}{ Girls } & \multicolumn{2}{|c|}{$\begin{array}{c}\text { Older } \\
\text { adolescents } \\
\end{array}$} & \multicolumn{2}{|c|}{$\begin{array}{c}\text { Younger } \\
\text { adolescents }\end{array}$} \\
\hline & & $\begin{array}{l}\text { AUC } \\
\text { (total) }\end{array}$ & $\begin{array}{l}\text { Cut- } \\
\text { off }\end{array}$ & $\begin{array}{l}\text { Sens/ } \\
\text { Spec }\end{array}$ & $\begin{array}{l}\text { Cut- } \\
\text { off }\end{array}$ & $\begin{array}{l}\text { Sens/ } \\
\text { Spec }\end{array}$ & $\begin{array}{l}\text { Cut- } \\
\text { off }\end{array}$ & $\begin{array}{l}\text { Sens/ } \\
\text { Spec }\end{array}$ & $\begin{array}{l}\text { Cut- } \\
\text { off }\end{array}$ & $\begin{array}{l}\text { Sens/ } \\
\text { Spec }\end{array}$ & $\begin{array}{l}\text { Cut- } \\
\text { off }\end{array}$ & $\begin{array}{c}\text { Sens/S } \\
\text { pec }\end{array}$ \\
\hline $\begin{array}{l}\text { RCADS-47- } \\
\text { Anxiety }\end{array}$ & 31 & .75 & 38.5 & $\begin{array}{l}.72 / \\
.69\end{array}$ & 26.5 & $\begin{array}{l}.77 / \\
.73\end{array}$ & 41.5 & $\begin{array}{l}.70 / \\
.67\end{array}$ & 38.5 & $\begin{array}{l}.77 / \\
.65\end{array}$ & 35.5 & $\begin{array}{l}.72 / \\
.66\end{array}$ \\
\hline $\begin{array}{l}\text { RCADS-25 - } \\
\text { Anxiety }\end{array}$ & 15 & .71 & 13.5 & $\begin{array}{l}.73 / \\
.61\end{array}$ & 10.9 & $\begin{array}{l}.70 / \\
.62\end{array}$ & 15.5 & $\begin{array}{l}.68 / \\
.61\end{array}$ & 14.5 & $\begin{array}{l}.70 / \\
.65\end{array}$ & 13.5 & $\begin{array}{l}.72 / \\
.61\end{array}$ \\
\hline Anx 1 & 12 & .79 & 15.5 & $\begin{array}{l}.73 / \\
.72\end{array}$ & 8.5 & $\begin{array}{l}.82 / \\
.72\end{array}$ & 17.5 & $\begin{array}{l}.72 / \\
.68\end{array}$ & 15.5 & $\begin{array}{l}.79 / \\
.71\end{array}$ & 14.5 & $\begin{array}{l}.73 / \\
.68\end{array}$ \\
\hline Anx 2 & 11 & .79 & 13.5 & $\begin{array}{l}.76 / \\
.68\end{array}$ & 9.5 & $\begin{array}{l}.83 / \\
.74\end{array}$ & 15.5 & $\begin{array}{l}.74 / \\
.66\end{array}$ & 14.5 & $\begin{array}{l}.78 / \\
.71\end{array}$ & 13.5 & $\begin{array}{l}.72 / \\
.70\end{array}$ \\
\hline Anx 3 & 10 & .80 & 12.5 & $\begin{array}{l}.75 / \\
.72\end{array}$ & 7.5 & $\begin{array}{l}.81 / \\
.72\end{array}$ & 13.5 & $\begin{array}{l}.74 / \\
.67\end{array}$ & 13.5 & $\begin{array}{l}.77 / \\
.75\end{array}$ & 11.5 & $\begin{array}{l}.76 / \\
.68\end{array}$ \\
\hline Anx 4 & 9 & .80 & 11.5 & $\begin{array}{l}.74 / \\
.73\end{array}$ & 7.5 & $\begin{array}{l}.79 / \\
.74\end{array}$ & 12.5 & $\begin{array}{l}.74 / \\
.67\end{array}$ & 12.5 & $\begin{array}{l}.76 / \\
.75\end{array}$ & 10.5 & $\begin{array}{l}.74 / \\
.69\end{array}$ \\
\hline Anx 5 & 8 & .80 & 10.5 & $\begin{array}{l}.77 / \\
.72\end{array}$ & 7.5 & $\begin{array}{l}.79 / \\
.77\end{array}$ & 11.5 & $\begin{array}{l}.75 / \\
.66\end{array}$ & 10.5 & $\begin{array}{l}.83 / \\
.70\end{array}$ & 9.5 & $\begin{array}{l}.79 / \\
.69\end{array}$ \\
\hline Anx 6 & 7 & .80 & 8.5 & $\begin{array}{l}.77 / \\
.72\end{array}$ & 5.5 & $\begin{array}{l}.81 / \\
.74\end{array}$ & 9.5 & $\begin{array}{l}.75 / \\
.67\end{array}$ & 8.5 & $\begin{array}{l}.82 / \\
.73\end{array}$ & 8.5 & $\begin{array}{l}.72 / \\
.71\end{array}$ \\
\hline Anx 7 & 6 & .81 & 7.5 & $\begin{array}{l}.77 / \\
.74\end{array}$ & 4.5 & $\begin{array}{l}.83 / \\
.75\end{array}$ & 8.5 & $\begin{array}{l}.73 / \\
.70\end{array}$ & 7.5 & $\begin{array}{l}.81 / \\
.78\end{array}$ & 7.5 & $\begin{array}{l}.74 / \\
.72\end{array}$ \\
\hline Anx 8 & 5 & .81 & 5.5 & $\begin{array}{l}.76 / \\
.73\end{array}$ & 3.5 & $\begin{array}{l}.86 / \\
.75\end{array}$ & 6.5 & $\begin{array}{l}.76 / \\
.70\end{array}$ & 5.5 & $\begin{array}{l}.79 / \\
.75\end{array}$ & 5.5 & $\begin{array}{l}.72 / \\
.71\end{array}$ \\
\hline Anx 9 & 4 & .81 & 3.5 & $\begin{array}{l}.83 / \\
.66\end{array}$ & 2.5 & $\begin{array}{l}.88 / \\
.74\end{array}$ & 4.5 & $\begin{array}{l}.76 / \\
.68\end{array}$ & 3.5 & $\begin{array}{l}.86 / \\
.68\end{array}$ & 3.5 & $\begin{array}{l}.81 / \\
.65\end{array}$ \\
\hline Anx 10 & 3 & .81 & 2.5 & $\begin{array}{l}.88 / \\
.71\end{array}$ & 2.5 & $\begin{array}{l}.85 / \\
.78\end{array}$ & 3.5 & $\begin{array}{l}.77 / \\
.69\end{array}$ & 3.5 & $\begin{array}{l}.77 / \\
.74\end{array}$ & 2.5 & $\begin{array}{l}.87 / \\
.62\end{array}$ \\
\hline Anx 11 & 2 & .81 & 1.5 & $\begin{array}{l}.82 / \\
.70\end{array}$ & 0.5 & $\begin{array}{l}.91 / \\
.65\end{array}$ & 1.5 & $\begin{array}{l}.85 / \\
.57\end{array}$ & 1.5 & $\begin{array}{l}.80 / \\
.65\end{array}$ & 1.5 & $\begin{array}{l}.83 / \\
.73\end{array}$ \\
\hline
\end{tabular}

Note. Anx 1-11= alternative anxiety item sets, Sens/Spec $=$ Sensitivity/Specificity.

\begin{tabular}{|c|c|c|c|c|c|c|c|c|c|c|c|c|}
\hline \multirow[b]{2}{*}{ Scale } & \multirow[b]{2}{*}{$\begin{array}{l}\text { Number } \\
\text { of items }\end{array}$} & \multicolumn{3}{|c|}{ Total } & \multicolumn{2}{|c|}{ Boys } & \multicolumn{2}{|c|}{ Girls } & \multicolumn{2}{|c|}{$\begin{array}{c}\text { Older } \\
\text { adolescents }\end{array}$} & \multicolumn{2}{|c|}{$\begin{array}{c}\text { Younger } \\
\text { adolescents }\end{array}$} \\
\hline & & $\begin{array}{c}\text { AUC } \\
\text { (total) }\end{array}$ & $\begin{array}{l}\text { Cut- } \\
\text { off }\end{array}$ & $\begin{array}{l}\text { Sens/ } \\
\text { Spec }\end{array}$ & $\begin{array}{l}\text { Cut- } \\
\text { off }\end{array}$ & $\begin{array}{l}\text { Sens/ } \\
\text { Spec }\end{array}$ & $\begin{array}{l}\text { Cut- } \\
\text { off }\end{array}$ & $\begin{array}{l}\text { Sens/ } \\
\text { Spec }\end{array}$ & $\begin{array}{l}\text { Cut- } \\
\text { off }\end{array}$ & $\begin{array}{l}\text { Sens/ } \\
\text { Spec }\end{array}$ & $\begin{array}{l}\text { Cut- } \\
\text { off }\end{array}$ & $\begin{array}{l}\text { Sens/ } \\
\text { Spec }\end{array}$ \\
\hline $\begin{array}{l}\text { RCADS-47 - } \\
\text { Depression }\end{array}$ & 10 & .86 & 14.7 & $\begin{array}{l}.83 / \\
.71\end{array}$ & 13.5 & $\begin{array}{l}.88 / \\
.77\end{array}$ & 15.5 & $\begin{array}{l}.75 / \\
.71\end{array}$ & 15.5 & $\begin{array}{l}.73 / \\
.72\end{array}$ & 16.8 & $\begin{array}{l}.86 / \\
.83\end{array}$ \\
\hline $\begin{array}{l}\text { RCADS-25 - } \\
\text { Depression }\end{array}$ & 10 & .86 & 14.7 & $\begin{array}{l}.83 / \\
.71 \\
.79 /\end{array}$ & 13.5 & $\begin{array}{l}.88 / \\
.77 \\
.80 /\end{array}$ & 15.5 & $\begin{array}{l}.75 / \\
.71 \\
.79 /\end{array}$ & 15.5 & $\begin{array}{l}.73 / \\
.72 \\
.77 /\end{array}$ & 16.8 & $\begin{array}{l}.86 / \\
.83 \\
.80 /\end{array}$ \\
\hline Depr 1 & 9 & .86 & 13.5 & $\begin{array}{l}.74 \\
.79 /\end{array}$ & 12.5 & $\begin{array}{c}.80 \\
1 /\end{array}$ & 13.5 & $\begin{array}{l}.68 \\
.79 /\end{array}$ & 13.5 & $\begin{array}{l}.68 \\
.77 /\end{array}$ & 14.5 & $\begin{array}{l}.79 \\
.85 /\end{array}$ \\
\hline Depr 2 & 8 & .87 & 12.5 & $\begin{array}{l}.78 \\
.81 /\end{array}$ & 10.5 & $\begin{array}{l}.78 \\
.94 /\end{array}$ & 12.5 & $\begin{array}{l}.73 \\
.81 /\end{array}$ & 12.5 & $\begin{array}{l}.75 \\
.79 /\end{array}$ & 12.5 & $\begin{array}{l}.79 \\
.85 /\end{array}$ \\
\hline Depr 3 & 7 & .87 & 10.5 & $\begin{array}{l}.74 \\
.81 /\end{array}$ & 9.5 & $\begin{array}{l}.80 \\
.88 /\end{array}$ & 10.5 & $\begin{array}{l}.69 \\
.82 /\end{array}$ & 10.5 & $\begin{array}{l}.69 \\
.79 /\end{array}$ & 10.5 & $\begin{array}{l}.77 \\
.86 /\end{array}$ \\
\hline Depr 4 & 6 & .86 & 9.5 & $\begin{array}{l}.76 \\
.82 /\end{array}$ & 8.5 & $\begin{array}{l}.80 \\
.88 /\end{array}$ & 9.5 & $\begin{array}{l}.71 \\
.82 /\end{array}$ & 9.5 & $\begin{array}{l}.71 \\
.79 /\end{array}$ & 9.5 & $\begin{array}{l}.78 \\
.90 /\end{array}$ \\
\hline Depr 5 & 5 & .87 & 8.5 & $\begin{array}{l}.77 \\
.89 /\end{array}$ & 7.5 & $\begin{array}{l}.83 \\
.88 /\end{array}$ & 8.5 & $\begin{array}{l}.71 \\
.89 /\end{array}$ & 8.5 & $\begin{array}{l}.70 \\
.86 /\end{array}$ & 8.5 & $\begin{array}{l}.80 \\
.90 /\end{array}$ \\
\hline Depr 6 & 4 & .86 & 5.5 & $\begin{array}{l}.70 \\
.77 /\end{array}$ & 5.5 & $\begin{array}{l}.82 \\
.88 /\end{array}$ & 5.5 & $\begin{array}{l}.63 \\
.76 /\end{array}$ & 5.5 & $\begin{array}{l}.64 \\
.72 /\end{array}$ & 6.5 & $\begin{array}{l}.82 \\
.90 /\end{array}$ \\
\hline Depr 7 & 3 & .86 & 4.5 & $\begin{array}{l}.77 \\
.83 /\end{array}$ & 3.5 & $\begin{array}{l}.78 \\
.88 /\end{array}$ & 4.5 & $\begin{array}{l}.73 \\
.80 /\end{array}$ & 4.5 & $\begin{array}{l}.71 \\
.80 /\end{array}$ & 4.5 & $\begin{array}{l}.81 \\
.90 /\end{array}$ \\
\hline Depr 8 & 2 & .84 & 2.5 & .70 & 2.5 & .77 & 2.5 & .66 & 2.5 & .62 & 2.5 & .74 \\
\hline
\end{tabular}

Note. Depr 1- Depr $8=$ Alternative depression item sets, Sens/Spec $=$ Sensitivity/Specificity. 


\section{Appendix C}

Adolescent-report

a) Rank-ordered item-discrimination indices for the suicidal ideation items

\begin{tabular}{llccc}
\hline \multirow{2}{*}{ Item name } & \multirow{2}{*}{ Item } & \multicolumn{3}{c}{ Item-depression diagnosis correlation } \\
\cline { 3 - 5 } & & Total & $\begin{array}{c}\text { Controlled } \\
\text { for Gender }\end{array}$ & $\begin{array}{c}\text { Controlled } \\
\text { for age }\end{array}$ \\
\hline MFQ19_T & I thought about killing myself. & $.39^{*}$ & $.39^{*}$ & $.40^{*}$ \\
MFQ16_T & I thought that life wasn't worth living. & $.36^{*}$ & $.35^{*}$ & $.35^{*}$ \\
MFQ17_T & I thought about death or dying. & $.32^{*}$ & $.32^{*}$ & $.33^{*}$ \\
MFQ18_T & $\begin{array}{l}\text { I thought my family would be better off without } \\
\text { me. }\end{array}$ & $.18^{*}$ & $.17^{*}$ & $.21^{*}$ \\
\hline
\end{tabular}

Note. MFQ-P16-19_T $=$ transformed MFQ items, ${ }^{*} p<.01$.

b) ROC curve analyses for 5 RCADS depression items with different combinations of suicidal ideation items

\begin{tabular}{|c|c|c|c|c|c|c|c|c|c|c|c|}
\hline & \multicolumn{2}{|c|}{ Total } & \multicolumn{3}{|c|}{ Boys } & \multicolumn{2}{|l|}{ Girls } & \multicolumn{2}{|c|}{$\begin{array}{c}\text { Older } \\
\text { adolescents }\end{array}$} & \multicolumn{2}{|c|}{$\begin{array}{c}\text { Younger } \\
\text { adolescents }\end{array}$} \\
\hline & $\begin{array}{l}\text { AUC } \\
\text { (total) }\end{array}$ & $\begin{array}{l}\text { Cut- } \\
\text { off }\end{array}$ & $\begin{array}{l}\text { Sens/ } \\
\text { Spec }\end{array}$ & $\begin{array}{l}\text { Cut- } \\
\text { off }\end{array}$ & $\begin{array}{l}\text { Sens/ } \\
\text { Spec }\end{array}$ & $\begin{array}{l}\text { Cut- } \\
\text { off }\end{array}$ & $\begin{array}{l}\text { Sens/ } \\
\text { Spec }\end{array}$ & $\begin{array}{l}\text { Cut- } \\
\text { off }\end{array}$ & $\begin{array}{l}\text { Sens/ } \\
\text { Spec }\end{array}$ & $\begin{array}{l}\text { Cut- } \\
\text { off }\end{array}$ & $\begin{array}{l}\text { Sens/ } \\
\text { Spec }\end{array}$ \\
\hline 5 Depression items & .87 & 8.5 & $\begin{array}{l}.82 / \\
.77\end{array}$ & 7.5 & $\begin{array}{l}.88 / \\
.83\end{array}$ & 8.5 & $\begin{array}{l}.82 / \\
.71\end{array}$ & 8.5 & $\begin{array}{l}.79 / \\
.70\end{array}$ & 8.5 & $\begin{array}{l}.90 / \\
.80\end{array}$ \\
\hline $\begin{array}{l}5 \text { Depression items } \\
+ \text { MFQ 19_T, MFQ } \\
16 \_T, \text { MFQ 17_T }\end{array}$ & .88 & 11.25 & $\begin{array}{l}.83 / \\
.76\end{array}$ & 10.3 & $\begin{array}{l}.92 / \\
.82\end{array}$ & 11.25 & $\begin{array}{l}.83 / \\
.72\end{array}$ & 11.75 & $\begin{array}{l}.80 / \\
.78\end{array}$ & 11.25 & $\begin{array}{l}.82 / \\
.78\end{array}$ \\
\hline $\begin{array}{l}5 \text { Depression items } \\
+ \text { MFQ 19_T, MFQ } \\
16 \_T\end{array}$ & .89 & 10.75 & $\begin{array}{l}.80 / \\
.79\end{array}$ & 10.25 & $\begin{array}{l}.92 / \\
.86\end{array}$ & 10.25 & $\begin{array}{l}.83 / \\
.73\end{array}$ & 10.75 & $\begin{array}{l}.80 / \\
.77\end{array}$ & 10.75 & $\begin{array}{l}.82 / \\
.81\end{array}$ \\
\hline $\begin{array}{l}5 \text { Depression items } \\
+ \text { MFQ 19_T }\end{array}$ & .89 & 9.25 & $\begin{array}{l}.83 / \\
.79\end{array}$ & 8.8 & $\begin{array}{l}.92 / \\
.85\end{array}$ & 9.25 & $\begin{array}{l}.83 / \\
.76\end{array}$ & 9.25 & $\begin{array}{l}.80 / \\
.78\end{array}$ & 9.25 & $\begin{array}{l}.91 / \\
.80\end{array}$ \\
\hline
\end{tabular}

Note. Sens/Spec $=$ Sensitivity/Specificity. MFQ-P16-19 T $=$ transformed MFQ-C items.

c) Summary of binary logistic regression for 5 RCADS depression items with and without suicidal ideation item

\begin{tabular}{|c|c|c|c|c|c|}
\hline Model & $b(S E)$ & $\begin{array}{l}\text { Wald } z- \\
\text { value }\end{array}$ & OR $(95 \% \mathrm{CI})$ & $\begin{array}{c}\text { McFadden's } \\
R^{2}\end{array}$ & $\begin{array}{l}\text { Model fit } \\
\text { change }\left(\chi^{2}\right)\end{array}$ \\
\hline \multicolumn{6}{|l|}{ Model 1} \\
\hline Constant & $-5.73(.58)$ & $-9.83 *$ & & .34 & $143.81^{* *}$ \\
\hline RCADS 5 depression items - A & $.51(.06)$ & $8.55^{*}$ & 1.66 & & \\
\hline \multicolumn{6}{|l|}{ Model 2} \\
\hline Constant & $-5.98(.77)$ & $-7.81 *$ & & .41 & $\begin{array}{c}6.23 \\
(p=.013)\end{array}$ \\
\hline RCADS 5 depression items - A & $.45(.08)$ & $5.55^{*}$ & $1.56[1.35-1.85]$ & & \\
\hline MFQ19_T & $.45(.18)$ & $\begin{array}{c}2.50 \\
(p=.012)\end{array}$ & $1.56[1.10-2.23]$ & & \\
\hline
\end{tabular}

Note. MFQ-19_T $=$ transformed MFQ-C item, A = adolescent-report, $* p<.01$. 
d) Rank-ordered item-discrimination indices for the symptom impact and duration items

\begin{tabular}{|c|c|c|c|c|}
\hline \multirow{2}{*}{ Item name } & \multirow{2}{*}{ Item } & \multicolumn{3}{|c|}{$\begin{array}{l}\text { Item-any anxiety/depressive disorder } \\
\text { diagnosis correlation }\end{array}$} \\
\hline & & Total & $\begin{array}{l}\text { Controlled } \\
\text { for Gender }\end{array}$ & $\begin{array}{l}\text { Controlled } \\
\text { for age }\end{array}$ \\
\hline $\begin{array}{l}\text { Impact - Family and } \\
\text { Friends }{ }^{\mathrm{a}}\end{array}$ & $\begin{array}{l}\text { How much of an impact do these difficulties have } \\
\text { on your family and friends? }\end{array}$ & $.53^{*}$ & $.51 *$ & $.52 *$ \\
\hline Impact - Distress & $\begin{array}{l}\text { How much do these difficulties upset or distress } \\
\text { you? }\end{array}$ & $.52 *$ & $.49^{*}$ & $.52 *$ \\
\hline Impact - School & $\begin{array}{l}\text { How much do these difficulties get in the way of } \\
\text { your everyday life in these areas (School) }\end{array}$ & $.52 *$ & $.50^{*}$ & $.50^{*}$ \\
\hline $\begin{array}{l}\text { Impact - Outside the } \\
\text { school }\end{array}$ & $\begin{array}{l}\text { How much do these difficulties get in the way of } \\
\text { your everyday life in these areas (Outside the } \\
\text { school) }\end{array}$ & $.44^{*}$ & $.42 *$ & $.42 *$ \\
\hline Impact - Friends & $\begin{array}{l}\text { How much do these difficulties get in the way of } \\
\text { your everyday life in these areas (Friends) }\end{array}$ & $.40^{*}$ & $.37 *$ & $.38^{*}$ \\
\hline Impact -Time & How long have you had these difficulties for? & $.34 *$ & $.31^{*}$ & $.30^{*}$ \\
\hline Impact - Home & $\begin{array}{l}\text { How much do these difficulties get in the way of } \\
\text { your everyday life in these areas (Home) }\end{array}$ & $.30^{*}$ & $.27^{*}$ & $.30^{*}$ \\
\hline
\end{tabular}

e) ROC curve analyses for 11 RCADS items with different combinations of symptom impact and duration items

\begin{tabular}{|c|c|c|c|c|c|c|c|c|c|c|c|}
\hline & \multicolumn{3}{|c|}{ Total } & \multicolumn{2}{|c|}{ Boys } & \multicolumn{2}{|c|}{ Girls } & \multicolumn{2}{|c|}{$\begin{array}{c}\text { Older } \\
\text { adolescents } \\
\end{array}$} & \multicolumn{2}{|c|}{$\begin{array}{c}\text { Younger } \\
\text { adolescents }\end{array}$} \\
\hline & $\begin{array}{c}\text { AUC } \\
\text { (total) }\end{array}$ & $\begin{array}{l}\text { Cut- } \\
\text { off }\end{array}$ & $\begin{array}{l}\text { Sens/ } \\
\text { Spec }\end{array}$ & $\begin{array}{l}\text { Cut- } \\
\text { off }\end{array}$ & $\begin{array}{l}\text { Sens/ } \\
\text { Spec }\end{array}$ & $\begin{array}{l}\text { Cut- } \\
\text { off }\end{array}$ & $\begin{array}{l}\text { Sens/ } \\
\text { Spec }\end{array}$ & $\begin{array}{c}\text { Cut- } \\
\text { off }\end{array}$ & $\begin{array}{l}\text { Sens/ } \\
\text { Spec }\end{array}$ & $\begin{array}{l}\text { Cut- } \\
\text { off }\end{array}$ & $\begin{array}{l}\text { Sens/ } \\
\text { Spec }\end{array}$ \\
\hline RCADS 11-item & & & $.80 /$ & & $.84 /$ & & $.72 /$ & & $.80 /$ & & $.78 /$ \\
\hline $\begin{array}{l}\text { Total } \\
\text { RCADS 11-item }\end{array}$ & .82 & 12.5 & .71 & 8.5 & .70 & 14.5 & .68 & 14.5 & .76 & 11.5 & .66 \\
\hline $\begin{array}{l}\text { Total + } 5 \text { Impact } \\
\text { items } \\
\text { RCADS 11-item }\end{array}$ & .84 & 22.5 & $\begin{array}{l}.82 / \\
.74\end{array}$ & 18.0 & $\begin{array}{l}.88 / \\
.78\end{array}$ & 24.5 & $\begin{array}{l}.75 / \\
.70\end{array}$ & 24.5 & $\begin{array}{l}.84 / \\
.78\end{array}$ & 21.5 & $\begin{array}{l}.76 / \\
.73\end{array}$ \\
\hline $\begin{array}{l}\text { Total + } 4 \text { Impact } \\
\text { items } \\
\text { RCADS 11-item }\end{array}$ & .85 & 19.5 & $\begin{array}{l}.83 / \\
.73\end{array}$ & 16.5 & $\begin{array}{l}.83 / \\
.78\end{array}$ & 21.5 & $\begin{array}{l}.77 / \\
.71\end{array}$ & 22.5 & $\begin{array}{l}.80 / \\
.79\end{array}$ & 18.5 & $\begin{array}{l}.76 / \\
.70\end{array}$ \\
\hline $\begin{array}{l}\text { Total }+3 \text { Impact } \\
\text { items } \\
\text { RCADS 11-item }\end{array}$ & .84 & 18.5 & $\begin{array}{l}.81 / \\
.73\end{array}$ & 14.5 & $\begin{array}{l}.88 / \\
.80\end{array}$ & 20.5 & $\begin{array}{l}.75 / \\
.70\end{array}$ & 20.5 & $\begin{array}{l}.84 / \\
.79\end{array}$ & 17.5 & $\begin{array}{l}.74 / \\
.71\end{array}$ \\
\hline $\begin{array}{l}\text { Total }+\mathbf{2} \\
\text { Impact items } \\
\text { RCADS } 11 \text {-item }\end{array}$ & .84 & 16.5 & $\begin{array}{l}.84 / \\
.72\end{array}$ & 13.5 & $\begin{array}{l}.88 / \\
.78\end{array}$ & 18.5 & $\begin{array}{l}.76 / \\
.66\end{array}$ & 18.6 & $\begin{array}{l}.86 / \\
.74\end{array}$ & 16.5 & $\begin{array}{l}.74 / \\
.72\end{array}$ \\
\hline $\begin{array}{l}\text { Total + } 1 \text { Impact } \\
\text { item }\end{array}$ & .83 & 14.5 & $\begin{array}{l}.83 / \\
.71\end{array}$ & 10.5 & $\begin{array}{l}.89 / \\
.71\end{array}$ & 17.5 & $\begin{array}{l}.72 / \\
.70\end{array}$ & 17.5 & $\begin{array}{l}.79 / \\
.79\end{array}$ & 14.5 & $\begin{array}{l}.73 / \\
.73\end{array}$ \\
\hline
\end{tabular}

f) Summary of binary logistic regression for total scale with and without symptom impact items (adolescent-report)

\begin{tabular}{|c|c|c|c|c|c|}
\hline Model & $b(S E)$ & Wald $z$-value & OR $(95 \% \mathrm{CI})$ & $\begin{array}{c}\text { McFadden's } \\
R^{2} \\
\end{array}$ & $\begin{array}{l}\text { Model fit } \\
\text { change }\left(\chi^{2}\right)\end{array}$ \\
\hline \multicolumn{6}{|l|}{ Model 1} \\
\hline Constant & $-2.44(.28)$ & $-8.81 *$ & & .28 & $142.47 *$ \\
\hline RCADS 11 item Total - A & $.19(.02)$ & $10.02 *$ & $1.21[1.64,1.25]$ & & \\
\hline \multicolumn{6}{|l|}{ Model 2} \\
\hline Constant & $-3.97(.44)$ & $-9.00 *$ & & .41 & $26.59 *$ \\
\hline RCADS 11 item Total - A & $.11(.03)$ & $4.37 *$ & $1.12[1.07,1.18]$ & & \\
\hline Impact items - A & $.62(.13)$ & $4.90 *$ & $1.85[1.46,2.40]$ & & \\
\hline
\end{tabular}

Note. $\mathrm{A}=$ adolescent-report, ${ }^{*} p<.01$. 
Parent-report

a) Rank-ordered item-discrimination indices for the suicidal ideation items

\begin{tabular}{llcccc}
\hline \multirow{2}{*}{ Item name } & \multirow{2}{*}{ Item } & \multicolumn{3}{c}{ Item-depression diagnosis correlation } \\
\cline { 3 - 5 } & & Total & $\begin{array}{c}\text { Controlled } \\
\text { for Gender }\end{array}$ & $\begin{array}{c}\text { Controlled } \\
\text { for age }\end{array}$ \\
\hline MFQ-P16_T & My child thought that life wasn't worth living & $.33^{*}$ & $.33^{*}$ & $.33^{*}$ \\
MFQ-P17_T & My child thought about death or dying & $.22^{*}$ & $.22^{*}$ & $.25^{*}$ \\
MFQ-P19_T & My child thought about killing himself/herself & $.21^{*}$ & $.21^{*}$ & $.22^{*}$ \\
MFQ-P18_T & $\begin{array}{l}\text { My child thought my family would be better off } \\
\text { without him/her }\end{array}$ & 0.05 & 0.04 & 0.08 \\
\hline Note.MFQ-P16-19 T $=$ transformed MFQ-P item ${ }^{*} p<01$ & & &
\end{tabular}

Note. MFQ-P16-19_T $=$ transformed MFQ-P item, ${ }^{*} p<.01$.

b) ROC curve analyses for 5 RCADS items plus different combinations of suicidal ideation items

\begin{tabular}{|c|c|c|c|c|c|c|c|c|c|c|c|}
\hline & \multicolumn{3}{|c|}{ Total } & \multicolumn{2}{|c|}{ Boys } & \multicolumn{2}{|c|}{ Girls } & \multicolumn{2}{|c|}{$\begin{array}{c}\text { Older } \\
\text { adolescents }\end{array}$} & \multicolumn{2}{|c|}{$\begin{array}{c}\text { Younger } \\
\text { adolescents }\end{array}$} \\
\hline & $\begin{array}{l}\text { AUC } \\
\text { (total) }\end{array}$ & $\begin{array}{l}\text { Cut- } \\
\text { off }\end{array}$ & $\begin{array}{l}\text { Sens/ } \\
\text { Spec }\end{array}$ & $\begin{array}{l}\text { Cut- } \\
\text { off }\end{array}$ & $\begin{array}{l}\text { Sens/ } \\
\text { Spec }\end{array}$ & $\begin{array}{l}\text { Cut- } \\
\text { off }\end{array}$ & $\begin{array}{l}\text { Sens/ } \\
\text { Spec }\end{array}$ & $\begin{array}{l}\text { Cut- } \\
\text { off }\end{array}$ & $\begin{array}{l}\text { Sens/ } \\
\text { Spec }\end{array}$ & $\begin{array}{l}\text { Cut- } \\
\text { off }\end{array}$ & $\begin{array}{l}\text { Sens/ } \\
\text { Spec }\end{array}$ \\
\hline 5 Depression items & .86 & 6.5 & $\begin{array}{l}.84 / \\
.75\end{array}$ & 5.5 & $\begin{array}{l}.93 / \\
.75\end{array}$ & 6.5 & $\begin{array}{l}.85 / \\
.72\end{array}$ & 6.5 & $\begin{array}{l}.82 / \\
.74\end{array}$ & 6.5 & $\begin{array}{l}.90 / \\
.76\end{array}$ \\
\hline $\begin{array}{l}5 \text { Depression items } \\
+ \text { MFQ } 19-\mathrm{T}, \mathrm{MFQ} \\
16 \_\mathrm{T}, \mathrm{MFQ} 17 \_\mathrm{T} \\
5 \text { Depression items } \\
+ \text { MFQ } 19 \mathrm{~T}, \mathrm{MFQ}\end{array}$ & .87 & 6.75 & $\begin{array}{l}.90 / \\
.77\end{array}$ & 6.5 & $\begin{array}{l}.90 / \\
.84\end{array}$ & 6.75 & $\begin{array}{l}.90 / \\
.74\end{array}$ & 6.5 & $\begin{array}{l}.86 / \\
.76\end{array}$ & 7.25 & $\begin{array}{l}.90 / \\
.84\end{array}$ \\
\hline $16 \mathrm{~T}-\mathrm{T}$ & .87 & 6.75 & .76 & 6.5 & .84 & 7.25 & .78 & 6.5 & .75 & 7.25 & .82 \\
\hline
\end{tabular}

Note. Sens/Spec $=$ Sensitivity/Specificity, MFQP-19_T $=$ transformed MFQ-P item.

c) Summary of binary logistic regression for 5 RCADS depression items with and without suicidal ideation item

\begin{tabular}{|c|c|c|c|c|c|}
\hline Model & $b(S E)$ & $\begin{array}{c}\text { Wald } z \text { - } \\
\text { value } \\
\text { (p-value) }\end{array}$ & OR $(95 \% \mathrm{CI})$ & $\begin{array}{c}\text { McFadden's } \\
R^{2}\end{array}$ & $\begin{array}{l}\text { Model fit } \\
\text { change }\left(\chi^{2}\right)\end{array}$ \\
\hline \multicolumn{6}{|l|}{ Model 1} \\
\hline Constant & $-4.41(.43)$ & $-10.36^{*}$ & & .32 & $111.16^{*}$ \\
\hline $\begin{array}{r}\text { RCADS } 5 \text { depression items - } \\
\text { - }\end{array}$ & $.43(.05)$ & $8.42 *$ & $1.66[1.49,1.89]$ & & \\
\hline \multicolumn{6}{|l|}{ Model 2} \\
\hline Constant & $-4.92(.57)$ & $-8.58 *$ & & .61 & $\begin{array}{c}.451 \\
(p=.502)\end{array}$ \\
\hline RCADS 5 depression items - & $.45(.07)$ & $6.43^{*}$ & $1.56[1.38-1.81]$ & & \\
\hline Impact items - A & $.15(.23)$ & $\begin{array}{c}.68 \\
(p=.497)\end{array}$ & $1.17[.73-1.81]$ & & \\
\hline
\end{tabular}

Note. MFQP-19_T $=$ transformed MFQ-P item, $\mathrm{P}=$ parent-report, ${ }^{*} p<.01$. 
d) Rank-ordered item-discrimination indices for the 11 RCADS items plus symptom impact and duration items

\begin{tabular}{|c|c|c|c|c|}
\hline \multirow[b]{2}{*}{ Item name } & \multirow[b]{2}{*}{ Item } & \multicolumn{3}{|c|}{ Item- anxiety diagnosis correlation } \\
\hline & & Total & $\begin{array}{l}\text { Controlled } \\
\text { for Gender }\end{array}$ & $\begin{array}{l}\text { Controlled } \\
\text { for age }\end{array}$ \\
\hline Impact-Distress & $\begin{array}{l}\text { How much do these difficulties upset or } \\
\text { distress your child? }\end{array}$ & $.65^{*}$ & $.63^{*}$ & $.65^{*}$ \\
\hline Impact-Family & $\begin{array}{l}\text { How much of an impact do these difficulties } \\
\text { have on you or the family as a whole? }\end{array}$ & $.60 *$ & $.58^{*}$ & $.61 *$ \\
\hline Impact-School & $\begin{array}{l}\text { How much do these difficulties get in the } \\
\text { way of your child's everyday life in these } \\
\text { areas? (School) }\end{array}$ & $.59^{*}$ & $.57 *$ & $.59 *$ \\
\hline $\begin{array}{l}\text { Impact-Outside the } \\
\text { school }\end{array}$ & $\begin{array}{l}\text { How much do these difficulties get in the } \\
\text { way of your child's everyday life in these } \\
\text { areas? (Outside the school) }\end{array}$ & $.58^{*}$ & $.56^{*}$ & $.58^{*}$ \\
\hline Impact-Home & $\begin{array}{l}\text { How much do these difficulties get in the } \\
\text { way of your child's everyday life in these } \\
\text { areas? (Home) }\end{array}$ & $.54 *$ & $.52 *$ & $.54 *$ \\
\hline Impact-Friends & $\begin{array}{l}\text { How much do these difficulties get in the } \\
\text { way of your child's everyday life in these } \\
\text { areas? (Friends) }\end{array}$ & $.49 *$ & $.46^{*}$ & $.49 *$ \\
\hline Impact-Time & $\begin{array}{l}\text { How long has your child had these } \\
\text { difficulties for? }\end{array}$ & $.23 *$ & $.21 *$ & $.24 *$ \\
\hline
\end{tabular}

$\overline{\text { Note. }}{ }^{*} p<.01$.

e) ROC curve analyses for different combinations of symptom impact and duration items

\begin{tabular}{|c|c|c|c|c|c|c|c|c|c|c|c|}
\hline & \multicolumn{3}{|c|}{$\begin{array}{l}\text { Total } \\
\text { Boys }\end{array}$} & \multicolumn{2}{|c|}{ Girls } & \multicolumn{3}{|c|}{ Older adolescents } & \multicolumn{3}{|c|}{ Younger adolescents } \\
\hline & $\begin{array}{c}\text { AUC } \\
\text { (total) }\end{array}$ & $\begin{array}{l}\text { Cut- } \\
\text { off }\end{array}$ & $\begin{array}{l}\text { Sens/ } \\
\text { Spec }\end{array}$ & $\begin{array}{l}\text { Cut- } \\
\text { off }\end{array}$ & $\begin{array}{l}\text { Sens/ } \\
\text { Spec }\end{array}$ & $\begin{array}{l}\text { Cut- } \\
\text { off }\end{array}$ & $\begin{array}{l}\text { Sens/ } \\
\text { Spec }\end{array}$ & $\begin{array}{l}\text { Cut- } \\
\text { off }\end{array}$ & $\begin{array}{l}\text { Sens/ } \\
\text { Spec }\end{array}$ & $\begin{array}{l}\text { Cut- } \\
\text { off }\end{array}$ & $\begin{array}{l}\text { Sens } \\
\text { Spec }\end{array}$ \\
\hline $\begin{array}{l}\text { RCADS 11- } \\
\text { itemTotal }\end{array}$ & .88 & 10.5 & $\begin{array}{l}.80 / \\
.79\end{array}$ & 7.5 & $\begin{array}{l}.96 / \\
.80\end{array}$ & 11.5 & $\begin{array}{l}.78 / \\
.75\end{array}$ & 9.5 & $\begin{array}{l}.84 / \\
.77\end{array}$ & 10.5 & $\begin{array}{l}.80 / \\
.77\end{array}$ \\
\hline $\begin{array}{l}\text { RCADS 11- } \\
\text { itemTotal - } \\
\text { matched to } \\
\text { adolescent-report }\end{array}$ & .89 & 14.5 & $\begin{array}{l}.82 / \\
.80\end{array}$ & 12.5 & $\begin{array}{l}.86 / \\
.84\end{array}$ & 14.5 & $\begin{array}{l}.87 / \\
.74\end{array}$ & 14.5 & $\begin{array}{l}.84 / \\
.83\end{array}$ & 14.5 & $\begin{array}{l}.80 / \\
.79\end{array}$ \\
\hline $\begin{array}{l}\text { RCADS } 11- \\
\text { itemTotal + } 6 \\
\text { Impact items }\end{array}$ & .90 & 20.5 & $\begin{array}{l}.84 / \\
.79\end{array}$ & 17.5 & $\begin{array}{l}.82 / \\
.82\end{array}$ & 22.5 & $\begin{array}{l}.83 / \\
.78\end{array}$ & 20.5 & $\begin{array}{l}.84 / \\
.80\end{array}$ & 20.5 & $\begin{array}{l}.85 / \\
.79\end{array}$ \\
\hline $\begin{array}{l}\text { RCADS } 11- \\
\text { itemTotal + } 5 \\
\text { Impact items }\end{array}$ & .90 & 19.5 & $\begin{array}{l}.82 / \\
.80\end{array}$ & 15.5 & $\begin{array}{l}.89 / \\
.84\end{array}$ & 21.5 & $\begin{array}{l}.81 / \\
.80\end{array}$ & 18.5 & $\begin{array}{l}.87 / \\
.80\end{array}$ & 19.6 & $\begin{array}{l}.81 / \\
.79\end{array}$ \\
\hline $\begin{array}{l}\text { RCADS 11- } \\
\text { itemTotal + } 4 \\
\text { Impact items }\end{array}$ & .90 & 18.5 & $\begin{array}{l}.81 / \\
.81\end{array}$ & 14.5 & $\begin{array}{l}.86 / \\
.84\end{array}$ & 19.5 & $\begin{array}{l}.83 / \\
.77\end{array}$ & 17.5 & $\begin{array}{l}.87 / \\
.80\end{array}$ & 18.5 & $\begin{array}{l}.80 / \\
.80\end{array}$ \\
\hline $\begin{array}{l}\text { RCADS 11- } \\
\text { itemTotal + } 3 \\
\text { Impact item }\end{array}$ & .90 & 16.5 & $\begin{array}{l}.81 / \\
.80\end{array}$ & 13.5 & $\begin{array}{l}.86 / \\
.84\end{array}$ & 17.5 & $\begin{array}{l}.84 / \\
.76\end{array}$ & 15.5 & $\begin{array}{l}.86 / \\
.80\end{array}$ & 16.5 & $\begin{array}{l}.80 / \\
.79\end{array}$ \\
\hline $\begin{array}{l}\text { RCADS 11- } \\
\text { itemTotal + } 2 \\
\text { Impact item }\end{array}$ & .90 & 14.5 & $\begin{array}{l}.82 / \\
.80\end{array}$ & 11.5 & $\begin{array}{l}.92 / \\
.82\end{array}$ & 15.5 & $\begin{array}{l}.81 / \\
.76\end{array}$ & 13.5 & $\begin{array}{l}.86 / \\
.80\end{array}$ & 14.5 & $\begin{array}{l}.82 / \\
.79\end{array}$ \\
\hline $\begin{array}{l}\text { RCADS 11- } \\
\text { item Total + } 1 \\
\text { Impact item }^{3}\end{array}$ & .89 & 12.5 & $\begin{array}{l}.83 / \\
.80\end{array}$ & 10.5 & $\begin{array}{l}.84 / \\
.84\end{array}$ & 13.5 & $\begin{array}{l}.83 / \\
.75\end{array}$ & 12.5 & $\begin{array}{l}.84 / \\
.83\end{array}$ & 12.5 & $\begin{array}{l}.81 / \\
.79\end{array}$ \\
\hline
\end{tabular}

Note. Sens/Spec $=$ Sensitivity/Specificity.

\footnotetext{
${ }^{3}$ The ROC curve analyses confirmed that the optimal parent-report total scale with one symptom impact item was not significantly different $(p=.62)$ from the parent-report total scale that included the same symptom impact items as adolescent adolescent-report total scale.
} 
f) Summary of binary logistic regression for the 11 RCADS items with and without symptom impact items

\begin{tabular}{|c|c|c|c|c|c|}
\hline \multicolumn{2}{|c|}{$b(S E)$} & $\begin{array}{c}\text { Wald } z- \\
\text { value } \\
(p \text {-value })\end{array}$ & OR $(95 \% \mathrm{CI})$ & McFadden's $R^{2}$ & \multirow[t]{2}{*}{$\begin{array}{c}\text { Model fit } \\
\text { change }\left(\chi^{2}\right)\end{array}$} \\
\hline Model 1 & & & & & \\
\hline Constant & $-2.74(.28)$ & $-9.94 *$ & $1.29[1.24,1.35]$ & .42 & $213.67^{*}$ \\
\hline RCADS 11 item Total - A & $.26(.02)$ & $11.02 *$ & & & \\
\hline \multicolumn{6}{|l|}{ Model 2} \\
\hline Constant & $-3.79(.40)$ & $-9.42 *$ & & .50 & $17.06^{*}$ \\
\hline RCADS 11 item Total - A & $.15(.03)$ & $4.52 *$ & $1.16[1.09,1.24]$ & & \\
\hline Impact items - P & $.53(.13)$ & $4.02 *$ & $1.69[1.31,2.20]$ & & \\
\hline
\end{tabular}




\section{Appendix D}

McDonald's omega coefficients with 95\% confidence intervals for 11 RCADS items/original RCADS and RCADS-25 anxiety/depression subscales and total scales - adolescent-report and parent-report

\begin{tabular}{lcccc}
\hline & & \multicolumn{3}{c}{ Clinic-referred sample } \\
\cline { 3 - 5 } & Community & Total sample & $\begin{array}{c}\text { Anxiety } \\
\text { subsample }\end{array}$ & $\begin{array}{c}\text { Depression } \\
\text { subsample }\end{array}$ \\
\hline RCADS 6 anxiety items - A & $.89[.87-.91]$ & $.72[.67-.78]$ & $.73[.67-.78]$ & $.70[.59-.80]$ \\
RCADS-Anxiety subscale - A & $.97[.96-.98]$ & $.94[.93-.95]$ & $.94[.93-.95]$ & $.93[.90-.95]$ \\
RCADS-25-Anxiety subscale - A & $.92[.90-.93]$ & $.86[.83-.88]$ & $.85[.82-.88]$ & $.81[.75-.88]$ \\
& & & & \\
RCADS 5 depression items - A & $.87[.85-.90]$ & $.88[.85-.90]$ & $.88[.85-.90]$ & $.72[.62-.82]$ \\
RCADS-Depression subscale - A & $.92[.91-.94]$ & $.90[.99-.92]$ & $.90[.87-.92]$ & $.82[.76 .-.88]$ \\
RCADS-25-Depression subscale - A & $.92[.91-.94]$ & $.90[.99-.92]$ & $.90[.87-.92]$ & $.82[.76 .-.88]$ \\
& & & & \\
RCADS 11 total items - A & $.92[.90-.93]$ & $.83[.80-.86]$ & $.80[.80-.87]$ & $.74[.65-.83]$ \\
RCADS-Total scale - A & $.97[.97-.98]$ & $.95[.94-.96]$ & $.95[.94-.96]$ & $.92[.89-.95]$ \\
RCADS-25-Total scale - A & $.95[.94-.96]$ & $.89[.87-.91]$ & $.90[.87-.92]$ & $.84[.78-.89]$ \\
& & & & \\
RCADS 6 anxiety items - P & $.90[.88-.92]$ & $.77[.73-.82]$ & $.77[.72-.82]$ & $.78[.69-.86]$ \\
RCADS-Anxiety - subscale - P & $.98[.97-.98]$ & $.94[.92-.95]$ & $.93[.92-.95]$ & $.93[.90-.95]$ \\
RCADS-25-Anxiety subscale - P & $.94[.92-.95]$ & $.85[.81-.88]$ & $.84[.80-.87]$ & $.82[.75-.89]$ \\
RCADS 5 depression items - P & $.90[.88-.92]$ & $.85[.82-.88]$ & $.85[.82-.89]$ & $.72[.62-.82]$ \\
RCADS-Depression subscale - P & $.94[.93-.95]$ & $.86[.83-.89]$ & $.86[.83-.89]$ & $.76[.67-.84]$ \\
RCADS-25-Depression subscale - P & $.94[.93-.95]$ & $.86[.83-.89]$ & $.86[.83-.89]$ & $.76[.67-.84]$ \\
RCADS 11 total items - P & $.94[.92-.95]$ & $.83[.79-.86]$ & $.84[.80-.87]$ & $.77[.70-.85]$ \\
RCADS-Total scale- P & $.97[.96-.98]$ & $.93[.92-.94]$ & $.93[.92-.94]$ & $.94[.93-.95]$ \\
Note. A = adolescent-report P P parent-report. & $.97[.96-.97]$ & $.89[.86-.91]$ & $.89[.87-.91]$ & $.82[.76-.89]$ \\
\hline
\end{tabular}


Appendix E

Convergent and divergent validity coefficients for RCADS 11 items/original RCADS-47/RCADS-25

\begin{tabular}{lcccc}
\hline & & \multicolumn{3}{c}{ MFQ-C/P - Clinic-referred Sample } \\
\cline { 3 - 5 } & $\begin{array}{c}\text { MFQ-C/P } \\
\text { Community Sample }\end{array}$ & Total sample & $\begin{array}{c}\text { Anxiety } \\
\text { subsample }\end{array}$ & $\begin{array}{c}\text { Depression } \\
\text { subsample }\end{array}$ \\
\hline RCADS 6 anxiety items - A & $.77^{*}$ & $.58^{*}$ & $.60^{*}$ & $.28(p=.083)$ \\
RCADS-Anxiety subscale - A & $.77^{*}$ & $.59^{*}$ & $.63^{*}$ & $.25(p .111)$ \\
RCADS-25-Anxiety subscale - A & $.76^{*}$ & $.55^{*}$ & $.59^{*}$ & $.20(p=.189)$ \\
& & & & \\
RCADS 5 depression items - A & $.80^{*}$ & $.77^{*}$ & $.77^{*}$ & $.63^{*}$ \\
RCADS-Depression subscale- A & $.85^{*}$ & $.80^{*}$ & $.80^{*}$ & $.53^{*}$ \\
RCADS-25-Depression subscale - A & $.85^{*}$ & $.80^{*}$ & $.80^{*}$ & $.53^{*}$ \\
& & & & $.53^{*}$ \\
RCADS 6 anxiety items - P & $.76^{*}$ & $.50^{*}$ & $.44(p=.011)$ \\
RCADS-Anxiety subscale - P & $.77^{*}$ & $.49^{*}$ & $.52^{*}$ & $.50^{*}$ \\
RCADS-25-Anxiety subscale - P & $.76^{*}$ & $.48^{*}$ & $.50^{*}$ & $.46^{*}$ \\
& & & & $.71^{*}$ \\
RCADS 5 depression items - P & $.79^{*}$ & $.70^{*}$ & $.71^{*}$ & $.67^{*}$ \\
RCADS-Depression subscale - P & $.85^{*}$ & $.71^{*}$ & $.72^{*}$ & $.67^{*}$ \\
RCADS-25-Depression subscale - P & $.85^{*}$ & $.71^{*}$ & $.72^{*}$ & \\
\hline Note. A = adolescent-report, P = parent-report, ${ }^{*} p<.01$. & & &
\end{tabular}




\section{Appendix F}

ROC curve analyses for the 11-item RCADS-P (current study), the original RCADS-P, and the RCADS-25-P

\begin{tabular}{|c|c|c|c|c|c|c|c|c|c|}
\hline \multirow{2}{*}{$\begin{array}{l}\text { Number of } \\
\text { items }\end{array}$} & \multicolumn{3}{|c|}{ RCADS: Anxiety } & \multicolumn{3}{|c|}{ RCADS: Depression } & \multicolumn{3}{|c|}{ RCADS: Total } \\
\hline & $6^{\mathrm{a}}$ & $37^{\mathrm{b}}$ & $15^{\mathrm{c}}$ & $5^{\mathrm{a}}$ & $10^{\mathrm{b}}$ & $10^{\mathrm{c}}$ & $11^{\mathrm{a}}$ & $47^{\mathrm{b}}$ & $25^{\mathrm{c}}$ \\
\hline \multicolumn{10}{|l|}{ Total } \\
\hline AUC & .86 & .83 & .82 & .86 & .84 & .84 & .88 & .86 & .86 \\
\hline Cut-off & 5.5 & 34.4 & 10.4 & 6.5 & 11.625 & 11.625 & 10.5 & 41.4 & 19.3 \\
\hline $\begin{array}{l}\text { Sensitivity/ } \\
\text { Specificity }\end{array}$ & $.80 / .77$ & $.73 / .73$ & $.74 / .73$ & $.84 / .75$ & $.81 / .74$ & $.81 / .74$ & $.80 / .79$ & $.78 / .75$ & $.77 / .77$ \\
\hline $\begin{array}{r}n \text { (positive; } \\
\text { negative) }\end{array}$ & $197 ; 227$ & $210 ; 227$ & $211 ; 225$ & $76 ; 364$ & $77 ; 373$ & $77 ; 373$ & $206 ; 214$ & $223 ; 214$ & $232 ; 214$ \\
\hline \multicolumn{10}{|l|}{ Boys } \\
\hline AUC & .90 & .87 & .84 & .88 & .85 & .85 & .91 & .88 & .88 \\
\hline Cut-off & 4.5 & 27.5 & 7.8 & 5.5 & 9.5 & 9.5 & 7.5 & 34.7 & 12.50 \\
\hline $\begin{array}{l}\text { Sensitivity/ } \\
\text { Specificity }\end{array}$ & $.84 / .83$ & $.81 / .77$ & $.76 / .75$ & $.93 / .75$ & $.86 / .72$ & $.86 / .72$ & $.96 / .80$ & $.82 / .80$ & $.92 / .78$ \\
\hline $\begin{array}{r}n \text { (positive; } \\
\text { negative) }\end{array}$ & $44 ; 93$ & $48 ; 93$ & $46 ; 93$ & $14 ; 129$ & $14 ; 130$ & $14 ; 130$ & $45 ; 91$ & $50 ; 91$ & $50 ; 91$ \\
\hline \multicolumn{10}{|l|}{ Girls } \\
\hline AUC & .83 & .81 & .8 & .84 & .84 & .84 & .86 & .83 & .84 \\
\hline Cut-off & 6.5 & 37.5 & 11.9 & 6.5 & 12.25 & 12.25 & 11.5 & 45.5 & 21.5 \\
\hline $\begin{array}{l}\text { Sensitivity/ } \\
\text { Specificity }\end{array}$ & $.75 / .75$ & $.75 / .72$ & $.74 / .70$ & $.85 / .72$ & $.79 / .73$ & $.79 / .73$ & $.78 / .75$ & $.76 / .72$ & $.75 / .72$ \\
\hline $\begin{array}{r}n \text { (positive; } \\
\text { negative) }\end{array}$ & $153 ; 134$ & $162 ; 134$ & $165 ; 132$ & $62 ; 235$ & $63 ; 243$ & $63 ; 243$ & $179 ; 117$ & $173 ; 123$ & $182 ; 123$ \\
\hline \multicolumn{10}{|l|}{$\begin{array}{l}\text { Older } \\
\text { adolescents }\end{array}$} \\
\hline AUC & .87 & .84 & .82 & .84 & .83 & .83 & .90 & .86 & .87 \\
\hline Cut-off & 4.5 & 32.9 & 9.5 & 6.5 & 11.625 & 11.625 & 9.5 & 35.4 & 17.5 \\
\hline $\begin{array}{l}\text { Sensitivity/ } \\
\text { Specificity }\end{array}$ & $.87 / .71$ & $.70 / .70$ & $.73 / .70$ & $.82 / .74$ & $.80 / .73$ & $.80 / .73$ & $.84 / .77$ & $.87 / .71$ & $.83 / .73$ \\
\hline $\begin{array}{r}n \text { (positive; } \\
\text { negative) }\end{array}$ & $98 ; 77$ & $105 ; 77$ & $106 ; 76$ & $56 ; 129$ & $56 ; 131$ & $56 ; 131$ & $109 ; 66$ & $116 ; 66$ & $120 ; 66$ \\
\hline \multicolumn{10}{|l|}{$\begin{array}{l}\text { Younger } \\
\text { adolescents }\end{array}$} \\
\hline AUC & .85 & .84 & .83 & .89 & .88 & .88 & .88 & .86 & .87 \\
\hline Cut-off & 5.5 & 35.5 & 10.9 & 6.5 & 12.25 & 12.25 & 10.5 & 39.5 & 19.4 \\
\hline $\begin{array}{l}\text { Sensitivity/ } \\
\text { Specificity }\end{array}$ & $.82 / .77$ & $.76 / .76$ & $.77 / .74$ & $.90 / .76$ & $.81 / .76$ & $.81 / .76$ & $.80 / .77$ & $.82 / .73$ & $.78 / .78$ \\
\hline $\begin{array}{r}n \text { (positive; } \\
\text { negative) }\end{array}$ & $99 ; 150$ & $105 ; 150$ & $105 ; 149$ & $20 ; 235$ & $21 ; 242$ & $21 ; 242$ & $97 ; 148$ & $107 ; 148$ & $112 ; 148$ \\
\hline
\end{tabular}




\section{Appendix G}

Anxiety and depression screening items with instructions

\section{Brief 11-item version of the RCADS for Adolescents \\ (adolescent-report)}

Please put a circle around the word that shows how often each of these things happens to you. There are no right or wrong answers.

\begin{tabular}{|l|l|l|l|l|}
\hline $\begin{array}{l}\text { 1. I have trouble going to school in the } \\
\text { mornings because I feel nervous or afraid }\end{array}$ & Never & Sometimes & Often & Always \\
\hline 2. I have no energy for things & Never & Sometimes & Often & Always \\
\hline 3. I worry when I go to bed at night & Never & Sometimes & Often & Always \\
\hline 4. I worry about what is going to happen & Never & Sometimes & Often & Always \\
\hline 5. Nothing is much fun anymore & Never & Sometimes & Often & Always \\
\hline $\begin{array}{l}\text { 6. All of a sudden I feel really scared for no } \\
\text { reason at all }\end{array}$ & Never & Sometimes & Often & Always \\
\hline $\begin{array}{l}\text { 7. I feel worthless } \\
\text { 8. I feel sad or empty }\end{array}$ & Never & Sometimes & Often & Always \\
\hline $\begin{array}{l}\text { 9. When I have a problem, my heart beats } \\
\text { really fast }\end{array}$ & Never & Sometimes & Often & Always \\
\hline 10. I am tired a lot & Never & Sometimes & Often & Always \\
\hline 11. I worry I might look foolish & Never & Sometimes & Often & Always \\
\hline
\end{tabular}

Impact supplement (optional):

Now please answer the following questions about those things that you said happen to you 'sometimes' 'often' or 'always'.

\begin{tabular}{|l|l|c|l|c|}
\hline $\begin{array}{l}\text { How much do these difficulties upset or } \\
\text { distress you? }\end{array}$ & Not at all & $\begin{array}{c}\text { Only a } \\
\text { little }\end{array}$ & Quite a lot & $\begin{array}{c}\text { A great } \\
\text { deal }\end{array}$ \\
\hline $\begin{array}{l}\text { How much do these difficulties get in the } \\
\text { way of your everyday life in school? }\end{array}$ & Not at all & $\begin{array}{c}\text { Only a } \\
\text { little }\end{array}$ & Quite a lot & $\begin{array}{c}\text { A great } \\
\text { deal }\end{array}$ \\
\hline
\end{tabular}




\section{Scoring:}

Never/not at all $=0$

Sometimes/only a little $=1$

Often/quite a lot $=2$

Always/a great deal $=3$

Anxiety scale (summarise items 1, 3, 4, 6, 9, 11):

Depression scale (summarise items 2, 5, 7, 8, 10):

Total scale (summarise all items):

Total scale + impact (total scale + impact items):

\section{Interpretation/cut-off scores:}

\begin{tabular}{|c|l|c|c|}
\hline \multicolumn{2}{|c|}{} & Boys & Girls \\
\hline Anxiety Scale & Symptoms & $\geq 5$ & $\geq 9$ \\
\hline Depression Scale & Symptoms & $\geq 8$ & $\geq 9$ \\
\hline \multirow{2}{*}{ Total Scale } & Symptoms & $\geq 9$ & $\geq 14$ \\
\cline { 2 - 4 } & Symptoms + Impact & $\geq 14$ & $\geq 18$ \\
\hline
\end{tabular}




\section{Brief 11-item version of the RCADS for Adolescents (parent-report)}

Please put a circle around the word that shows how often each of these things happens for your child.

\begin{tabular}{|l|l|l|l|l|}
\hline $\begin{array}{l}\text { 1. My child has trouble going to school in } \\
\text { the mornings because of feeling nervous or } \\
\text { afraid }\end{array}$ & Never & Sometimes & Often & Always \\
\hline 2. My child has no energy for things & Never & Sometimes & Often & Always \\
\hline 3. My child worries when in bed at night & Never & Sometimes & Often & Always \\
\hline $\begin{array}{l}\text { 4. My child worries about what is going to } \\
\text { happen }\end{array}$ & Never & Sometimes & Often & Always \\
\hline $\begin{array}{l}\text { 5. Nothing is much fun for my child } \\
\text { anymore }\end{array}$ & Never & Sometimes & Often & Always \\
\hline $\begin{array}{l}\text { 6. All of a sudden my child will feel really } \\
\text { scared for no reason at all }\end{array}$ & Never & Sometimes & Often & Always \\
\hline $\begin{array}{l}\text { 7. My child feels worthless } \\
\text { 8. My child feels sad or empty }\end{array}$ & Never & Sometimes & Often & Always \\
\hline $\begin{array}{l}\text { 9. When my child has a problem, his/her } \\
\text { heart beats really fast }\end{array}$ & Never & Sometimes & Often & Always \\
\hline 10. My child is tired a lot & Never & Sometimes & Often & Always \\
\hline 11. My child worries about looking foolish & Never & Sometimes & Often & Always \\
\hline
\end{tabular}

Impact supplement (optional):

Now please answer the following questions about those things that you said happen to your child 'sometimes' 'often' or 'always'.

\begin{tabular}{|l|l|c|l|c|}
\hline $\begin{array}{l}\text { How much do these difficulties upset or } \\
\text { distress your child? }\end{array}$ & Not at all & $\begin{array}{c}\text { Only a } \\
\text { little }\end{array}$ & Quite a lot & $\begin{array}{c}\text { A great } \\
\text { deal }\end{array}$ \\
\hline $\begin{array}{l}\text { How much do these difficulties get in the } \\
\text { way of your child's everyday life in school? }\end{array}$ & Not at all & $\begin{array}{c}\text { Only a } \\
\text { little }\end{array}$ & Quite a lot & $\begin{array}{c}\text { A great } \\
\text { deal }\end{array}$ \\
\hline
\end{tabular}




\section{Scoring:}

Never/not at all $=0$

Sometimes/only a little $=1$

Often/quite a lot $=2$

Always/a great deal $=3$

Anxiety scale (summarise items 1, 3, 4, 6, 9, 11):

Depression scale (summarise items 2, 5, 7, 8, 10):

Total scale (summarise all items):

Total scale + impact (total scale + impact items):

Interpretation/cut-off scores:

\begin{tabular}{|c|l|c|c|}
\hline \multicolumn{2}{|l|}{} & Boys & Girls \\
\hline Anxiety Scale & Symptoms & $\geq 5$ & $\geq 7$ \\
\hline Depression Scale & Symptoms & $\geq 6$ & $\geq 7$ \\
\hline \multirow{2}{*}{ Total Scale } & Symptoms & $\geq 8$ & $\geq 11$ \\
\cline { 2 - 4 } & Symptoms + Impact & $\geq 13$ & $\geq 15$ \\
\hline
\end{tabular}

